\title{
The Biology of Polymorphic Melanic Side-Spotting Patterns in Poeciliid Fishes
}

\section{Tanja C. Zerulla* and Philip K. Stoddard}

Institute of Environment, Department of Biological Sciences, Florida International University, Miami, FL, United States

Melanin-based color patterns are an emerging model for studying molecular and evolutionary mechanisms driving phenotypic correlations. Extensive literature exists on color patterns and their correlated traits in the family Poeciliidae, indicating that these fishes are tractable models. We review the biology of polymorphic melanic side-spotting patterns characterized by macromelanophores forming irregular spotted patterns across fishes' flanks. These patterns are present in the genera Gambusia, Limia, Phalloceros, Poecilia, and Xiphophorus. Their presence is controlled by dominant genes on autosomes or sex chromosomes. Variation in expression is under polygenic control; however, these genes' identities are still largely unknown. In some Gambusia holbrooki and Poecilia latipinna, expression is dependent on low temperature exposure, but underlying molecular mechanisms are unknown. Spotted fish develop melanoma in rare cases and are a well-developed model for melanoma research. Little is known about other physiological correlates except that spotted G. holbrooki males exhibit higher basal cortisol levels than unspotted males and that metabolic rate does not differ between morphs in some Xiphophorus species. Behavioral differences between morphs are widespread, but specific to population, species, and social context. Spotted G. holbrooki males appear to be more social and more dominant. Juvenile spotted G. holbrooki have lower behavioral flexibility, and spotted $X$. variatus exhibit greater stress resistance. Findings conflict on whether morphs differ in sexual behavior and in sexual selection by females. Melanic side-spotting patterns are uncommon $(<30 \%)$ in populations, although extreme high-frequency populations exist. This low frequency is surprising for dominant genes, indicating that a variety of selective pressures influence both these patterns and their correlated traits. Little is known about reproductive life history traits. Spotted G. holbrooki are larger and have higher survival when uncommon, but underlying mechanisms remain unknown. Spotted morphs appear to have a strong selective advantage during predation. Predators prefer to attack and consume unspotted morphs; however, this preference disappears when spotted G. holbrooki males are common, indicating negative frequency-dependent selection. Spotted morphs are preferred socially under turbid conditions, but other environmental factors that shape phenotypic correlations and morph fitness have not been studied. Finally, we present questions for future studies on melanic side-spotting patterns.

Keywords: color polymorphism, coloration, melanism, phenotypic integration, pigmentation, pleiotropy, trait associations 


\section{INTRODUCTION}

Poeciliidae are live-bearing fish of the sub-tropical and tropical waters of the Americas and Caribbean, a family that includes mollies, guppies, swordtails, platyfish, mosquitofish, limia, and others (Meffe and Snelson, 1989; Evans et al., 2011). Melanin polychromism has been observed in poeciliids since the late 1800's (Myers, 1925; Gordon and Gordon, 1957). These polymorphic patterns correlate with other traits, indicating that poeciliids have strong potential as a model taxonomic group for understanding the mechanisms, trends, and evolution of pigmentation-phenotype correlations common across the animal kingdom. A wealth of literature exists on poeciliid genetics, developmental biology, physiology, behavior, ecology, and evolution (for overviews, we recommend: Meffe and Snelson, 1989; Evans et al., 2011). Furthermore, poeciliids are an amenable group for laboratory and field experiments, being relatively easy to capture. Their small size and quick acclimatization to laboratory conditions, as well as their well-documented animal husbandry, makes them easy to maintain and handle for experiments. Poeciliids are also relatively easy to breed and have short generation times, which permits large-scale genetic and evolutionary studies. These features make them attractive over other taxa that may be more difficult to study, such as birds or mammals.

Previous reviews have focused on multiple color patterns and their related traits within a single species or genus of Poeciliidae (revs.: Basolo, 2006; Culumber, 2014). Here we focus on a polychromism that has arisen repeatedly across poeciliid species: the melanic side-spotting pattern, in which fish develop irregularly distributed black spots across their flanks. We propose that this polychromism is a potential model for investigating trait correlation patterns across populations and species, as well as for understanding the molecular and evolutionary mechanisms that lead to these similar correlations. Specifically, we describe the development, inheritance, and genetics of the melanic side-spotting pattern. We review trends in correlations with physiological and behavioral traits, as well as ecological selective pressures and evolutionary origins that possibly shape the polychromism. Although the melanic sidespotting pattern exists in multiple poeciliid species, most research has been focused on the swordtails, genus Xiphophorus, due to their development as a laboratory model of melanoma, and on Eastern Mosquitofish (Gambusia holbrooki) because it is a common and easily accessible species. Consequently, a species bias is present in this review, so we recommend that any noted trends be thoroughly investigated in other poeciliids. Furthermore, most studies have not been repeated within a species and are limited to only a few populations or breeding lines within a species, so we encourage further studies to validate the limited trait correlations identified and presented in this review within and across species. We highlight what is still unknown about the melanic side-spotting pattern and suggest areas of further research throughout the review.

\section{MECHANISMS OF PIGMENTATION-PHENOTYPE CORRELATION}

Correlations between color pattern and other phenotypic traits can arise through a variety of molecular and evolutionary mechanisms. The first potential evolutionary mechanism is correlational selection, in which similar selective pressures acting on separate genes results in a non-functional correlation between the melanic side-spotting pattern and another trait (Figure 1A; revs.: Sinervo and Svensson, 2002; Gray and McKinnon, 2007; Forsman et al., 2008; McKinnon and Pierotti, 2010; Peiman and Robinson, 2017; San-Jose and Roulin, 2018). Correlational selection is rare (rev.: McKinnon and Pierotti, 2010), as it usually leads to the second potential mechanism: co-adaptive selection. If these traits experience similar selective pressures, fish expressing both the pattern and the other trait would have increased fitness over those expressing one phenotype alone, so the separate genes for each trait are favored to be inherited together (Figure 1B; revs.: Sinervo and Svensson, 2002; McKinnon and Pierotti, 2010). Alternatively, these separate genes can be inherited together if the fitness of the color pattern depends on the expression of the other trait or vice versa (co-dependence; Figure 1C; revs.: Gray and McKinnon, 2007; Forsman et al., 2008; Peiman and Robinson, 2017; San-Jose and Roulin, 2018), or if the color pattern and other trait must both be expressed and working together for a shared function (co-specialization; Figure 1D, rev.: Peiman and Robinson, 2017).

Correlations can also arise due to shared molecular mechanisms (revs.: Ducrest et al., 2008; McKinnon and Pierotti, 2010; San-Jose and Roulin, 2018). Traits controlled by separate genes may be correlated through sequential causation, in which one trait is the precursor for another trait (Figure 1E, rev.: Peiman and Robinson, 2017). For example, a physiological change in hormones may be required first to initiate expression of the color pattern. Alternatively, these separate genes may have similar transcriptional regulation, such as through a shared promoter, that results in co-expression of the two different traits (Figure 1F; rev.: McKinnon and Pierotti, 2010). Genes that act on separate traits can also be inherited together if they are located close together on the same chromosome, as in linkage disequilibrium (Figure 1G; revs.: Sinervo and Svensson, 2002; Ducrest et al., 2008; McKinnon and Pierotti, 2010; Peiman and Robinson, 2017; San-Jose and Roulin, 2018). For example, the $P$ (pituitary) locus is associated with differences in sexual maturity and mating strategy in Xiphophorus (Kallman and Borkoski, 1978; Lampert et al., 2010) and is close to the pigmentation locus on the $Y$ chromosome (Kallman, 1983). Finally, genes and molecules rarely have a single biological function. Genes or molecular systems with multiple functions can thus affect multiple, separate traits through pleiotropy (Figure 1H; revs.: Sinervo and Svensson, 2002; Ducrest et al., 2008; McKinnon and Pierotti, 2010; Peiman and Robinson, 2017; San-Jose and Roulin, 2018). The melanocortin system is a key candidate that has been proposed to pleiotropically regulate pigmentation and other traits (revs.: Ducrest et al., 2008; 


\section{Evolutionary Mechanisms}

A. Correlational Selection

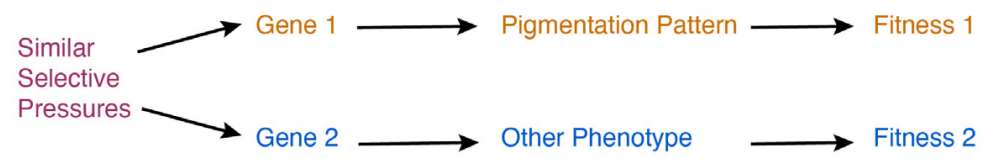

B. Co-Adaptive Selection

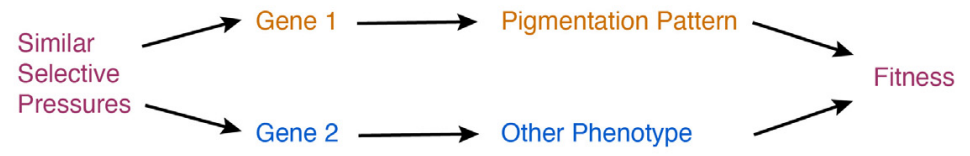

C. Co-Dependence

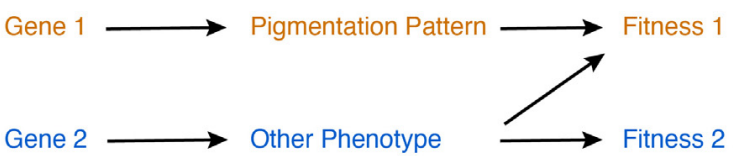

\section{Co-Specialization}

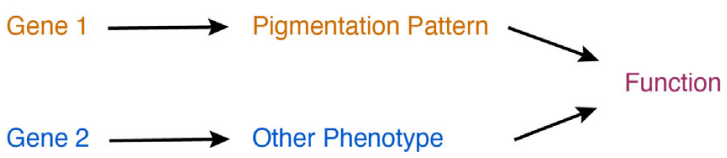

\section{Molecular Mechanisms}

\section{E. Sequential Causation}

Gene 2

Other Phenotype

Pigmentation Pattern

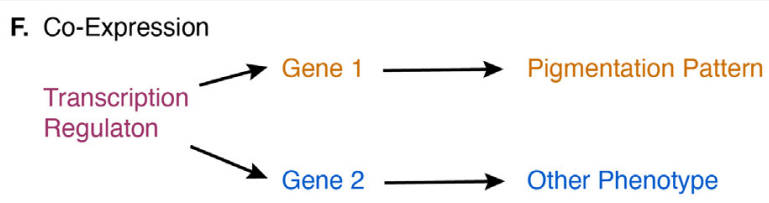

\section{G. Linkage Disequilibrium}
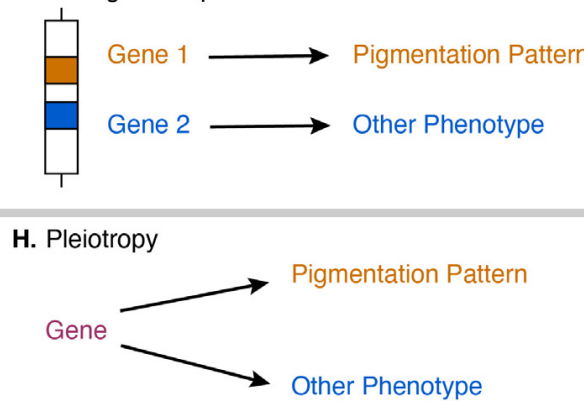

FIGURE 1 | Diagram of proposed evolutionary mechanisms (A-D) and molecular mechanisms (E-H) of phenotypic correlation. Pathway component colors indicate whether they are specific to the pigmentation pattern (orange), specific to a correlated phenotype (blue), or function in both pathways (purple).

San-Jose and Roulin, 2018). Melanocortins are pituitary peptide hormones that regulate melanin synthesis, rapid distribution of pigment in a cell, glucocorticoid release, energy balance, food intake, aggression, and sexual activity. However, melanocortins are not the only possible mechanism for pleiotropy; many endocrine and neuroendocrine substances are involved in the regulation of both pigmentation and other traits, including other peptide hormones, amino acid hormones (e.g., thyroid 

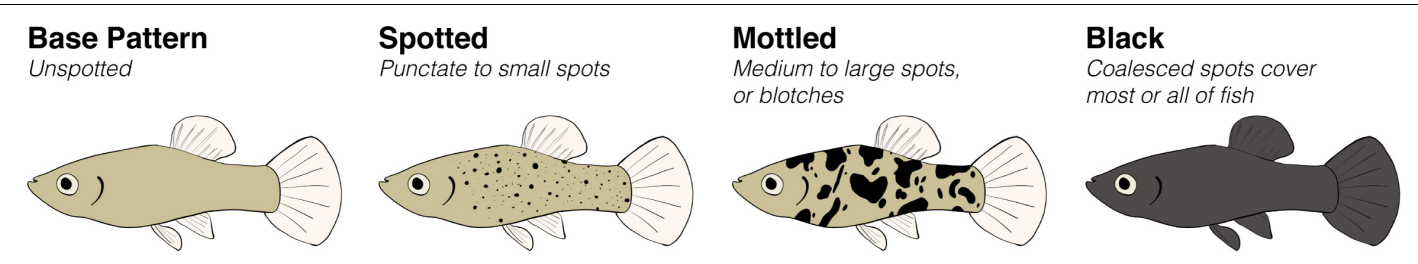

FIGURE 2 | Representation of the poeciliid pigmentation patterns included in this review. The base pattern lacks macromelanophores, so we interchangeably refer to it as "unspotted." Melanic side-spotting patterns include any pattern in poeciliid fishes that consists of macromelanophores forming spots that are irregularly distributed on the fish's flank. Included melanic side-spotting patterns may also extend into fins or be restricted to only a portion of the flank, not pictured here. The black morph is an extreme version of the spotting pattern.

hormone, GABA), monoamines (e.g., serotonin, dopamine), and sex steroids (e.g., testosterone). Neural crest cells have recently been proposed as a developmental mechanism for pleiotropy, as they differentiate into a variety of cells including pigment cells, neural cells, and endocrine cells (revs: Wilkins et al., 2014; San-Jose and Roulin, 2020). Determining which mechanism (or combination of mechanisms) underlies the specific correlations between melanic side-spotting patterns and other traits is not possible in a single study (San-Jose and Roulin, 2017), and will require multiple research groups working in parallel on different aspects of the biology of melanic side-spotting patterns and their correlated traits across different populations and species.

\section{MELANIC SPOTTING PATTERNS}

\section{Pattern Description}

The base pigmentation pattern of poeciliids is a gray-olivaceous color, created by small pigment cells called micromelanophores outlining the fish's scales in a reticulate pattern (Gordon, 1927, 1928; Anders et al., 1984). Because this base pattern does not have any defined spots, we use the term "unspotted" interchangeably throughout this review (Figure 2). Other color patterns overlay this base pattern, including those created by large pigment cells called macromelanophores (Gordon, 1927, 1928). This review focuses on what we term "melanic side-spotting patterns" that encompass a polychromism with a similar phenotype across poeciliid species and genera in which macromelanophores form irregularly distributed black spots on the fish's flanks (Figure 2). These melanic side-spotting patterns can vary in amount and size of spots and in whether they are composed of punctate spots or spots that have coalesced into blotches (Figure 2; Bellamy, 1936; Gordon and Gordon, 1957; Regan, 1961; Atz, 1962; Borowsky, 1973; Trendall and Johnson, 1981; Angus, 1983). To meet our criteria, the spotting pattern has to occur at minimum somewhere on the flank, but location of spotting on the flank can vary among species. While some species express spots over their whole body including head and fins (e.g., G. holbrooki), spots in other species are restricted to specific sections of the flank, such as dorsally of the mid-lateral line (e.g., Xiphophorus birchmanni). We do not include micromelanophore or macromelanophore spotting patterns expressed only in fins, that form single or twin spots on the flank or caudal peduncle, or that form stripes or bars. These patterns either overlap with species that express the pattern as a fixed trait (e.g., stripe in Heterandria formosa) or have only been studied in depth for a single genus (e.g., tail spots on the caudal peduncle of Xiphophorus).

Although phenotypically similar, melanic side-spotting patterns can differ from each other in terms of genetics, inheritance, sex, development, and organization, which is why some patterns have unique names to differentiate them in the literature (Table 1). We thus recommend that researchers always include images and specific descriptions and features of the pattern that include key terms like "side-spotted" to ensure that published literature is searchable and accessible for those not familiar with species-specific color patterns. Spotted morphs also have been referred to as melanic, melanistic, or black in the past; we advise that these terms be reserved for all-black morphs to avoid confusion, and recommend using descriptors like spotted, mottled, or blotched instead.

\section{Pigment Cells}

Melanophore differentiation has been reviewed extensively (revs.: Anders and Anders, 1978; Vielkind and Vielkind, 1982; Anders et al., 1984; Parichy and Spiewak, 2015). Briefly, all melanophores originate from neural crest cells (Humm and Young, 1956; Vielkind et al., 1976, 1982). Pigment progenitor cells ("chromatoblasts") from the neural crest migrate across the body. These pigment progenitor cells then differentiate into melanophore progenitor cells ("melanoblasts"), which can either divide clonally or differentiate further. Melanophore progenitor cells differentiate irreversibly into either micro- or macromelanophore progenitor cells, which eventually differentiate terminally into micro- and macromelanophores (Figure 3).

While micromelanophores differentiate in waves during embryonic stages to create the base pigmentation pattern, macromelanophores begin differentiation simultaneously and do so later in the fish's life to create spotting patterns (Humm and Young, 1956; Vielkind et al., 1976, 1982). Macromelanophores are 150-300 $\mu \mathrm{m}$ in diameter, approximately three times the size of micromelanophores measured in G. holbrooki (Regan, 1961; Kottler et al., 2020). Unlike micromelanophores, macromelanophores do not appear to have distance-dependent regulation, so they can overlap each other to form larger spots or blotches (Vielkind et al., 1982; Anders et al., 1984). Both melanophore types have dendritic or stellate shapes, but macromelanophores have 
TABLE 1 | Summary of the specific poeciliid pigmentation patterns included under the "melanic side-spotting pattern" definition of this review.

\begin{tabular}{|c|c|c|c|c|c|c|c|}
\hline Species & Pattern name & Representative photo & Pattern description & $\begin{array}{l}\text { Wild or } \\
\text { lab? }\end{array}$ & Sex & Inheritance & References \\
\hline $\begin{array}{l}\text { Gambusia } \\
\text { holbrooki }\end{array}$ & $\begin{array}{l}\text { Spotted, } \\
\text { mottled, } \\
\text { melanistic, } \\
\text { melanic }\end{array}$ & Photo by the authors & $\begin{array}{l}\text { Small to large blotches } \\
\text { on flanks, head, and } \\
\text { fins }\end{array}$ & Wild & Male & Y chromosome & $\begin{array}{l}\text { Myers, 1925; } \\
\text { Regan, 1961; } \\
\text { Angus, 1989; } \\
\text { Horth, 2006; } \\
\text { Kottler et al., } \\
2020\end{array}$ \\
\hline $\begin{array}{l}\text { Phalloceros } \\
\text { caudimacultus }\end{array}$ & $\begin{array}{l}\text { Spotted, } \\
\text { melanistic, } \\
\text { melanic, } \\
\text { mottled, } \\
\text { blotched }\end{array}$ & $\begin{array}{l}\text { Photo licensed under a Creative } \\
\text { Commons agreement }{ }^{1} \text {. }\end{array}$ & $\begin{array}{l}\text { Small to large blotches } \\
\text { on the flanks, head, } \\
\text { and fins }\end{array}$ & Wild & Both & Autosomal & $\begin{array}{l}\text { Myers, 1925; } \\
\text { Trendall and } \\
\text { Johnson, 1981; } \\
\text { McDowall, } \\
\text { 1999; Gutiérrez } \\
\text { and García, } \\
\text { 2007, 2011; } \\
\text { McNeil and } \\
\text { Wilson, } 2008\end{array}$ \\
\hline $\begin{array}{l}\text { Poecilia } \\
\text { formosa }\end{array}$ & Spotted & Refer to photo for spotted P. latipinna & $\begin{array}{l}\text { Small to large blotches } \\
\text { on the flanks, head, } \\
\text { and fins }\end{array}$ & Lab & $\begin{array}{l}\text { Clonal } \\
\text { female that } \\
\text { develops } \\
\text { as male }\end{array}$ & $\begin{array}{l}\text { Paternal micro- } \\
\text { chromosomes }\end{array}$ & $\begin{array}{l}\text { Haskins et al., } \\
\text { 1960; Schultz } \\
\text { and Kallman, } \\
\text { 1968; Turner } \\
\text { et al., 1980; } \\
\text { Schartl et al., } \\
\text { 1997; Lampert } \\
\text { et al., 2007; } \\
\text { Nanda et al., } \\
\text { 2007; } \\
\text { Lamatsch et al., } \\
\text { 2010, } 2011\end{array}$ \\
\hline & Black & $\begin{array}{l}\text { Photos licensed under a Creative } \\
\text { Commons agreement. }\end{array}$ & $\begin{array}{l}\text { Extreme form of } \\
\text { spotting in which spots } \\
\text { coalesce to cover } \\
\text { almost or all of the body }\end{array}$ & Lab & Both & $\begin{array}{l}\text { Autosomal } \\
\text { (single gene) }\end{array}$ & Schröder, 1964 \\
\hline $\begin{array}{l}\text { Poecilia } \\
\text { mexicana }\end{array}$ & Spotted & Refer to photo for spotted P. latipinna & $\begin{array}{l}\text { Small to large blotches } \\
\text { on the flanks, head, } \\
\text { and fins }\end{array}$ & Wild & Both & Autosomal & $\begin{array}{l}\text { Schröder, } \\
\text { 1964; Menzel } \\
\text { and Darnell, } \\
\text { 1973; } \\
\text { Culumber et al., } \\
2014\end{array}$ \\
\hline
\end{tabular}


TABLE 1 | Continued

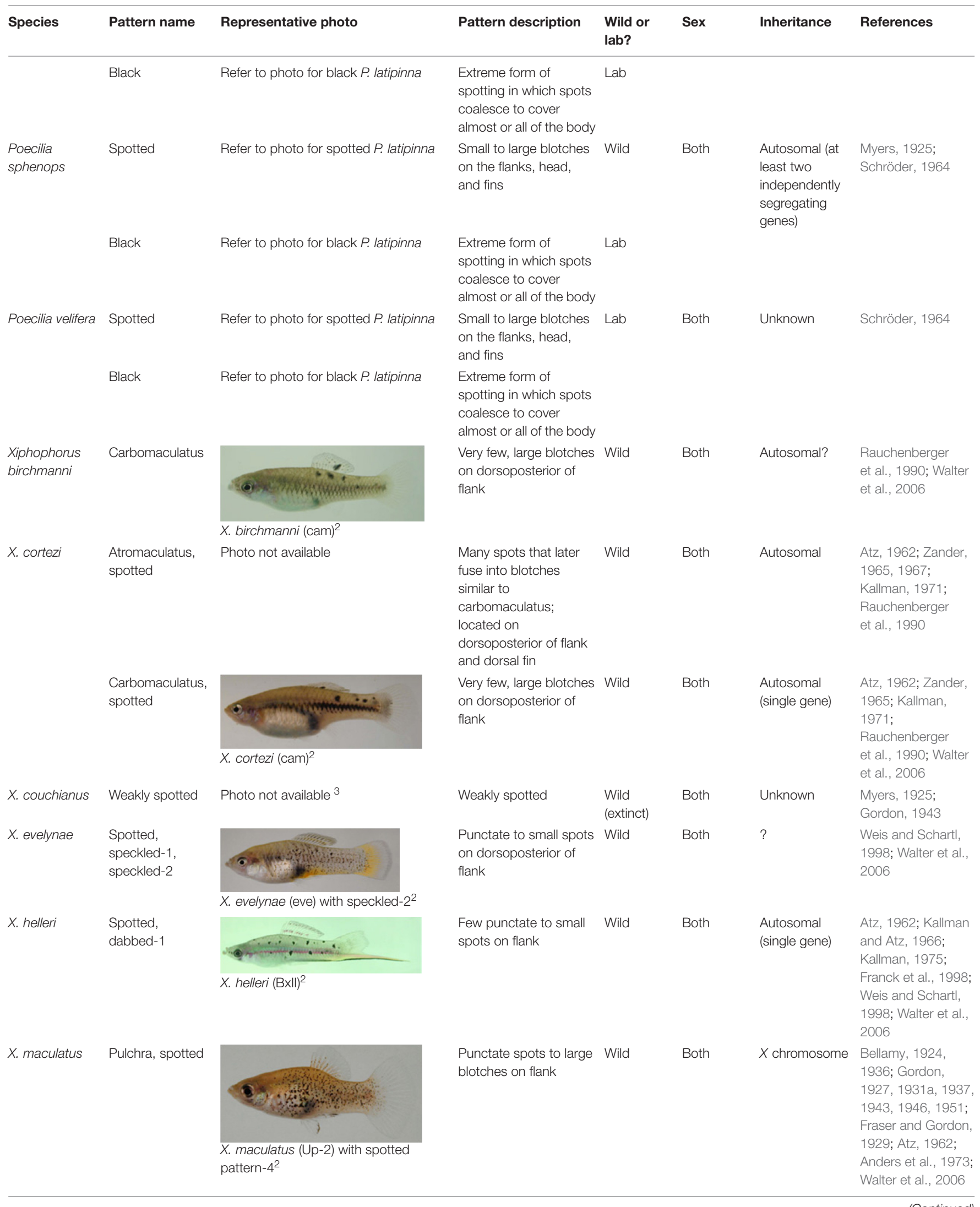


TABLE 1 | Continued

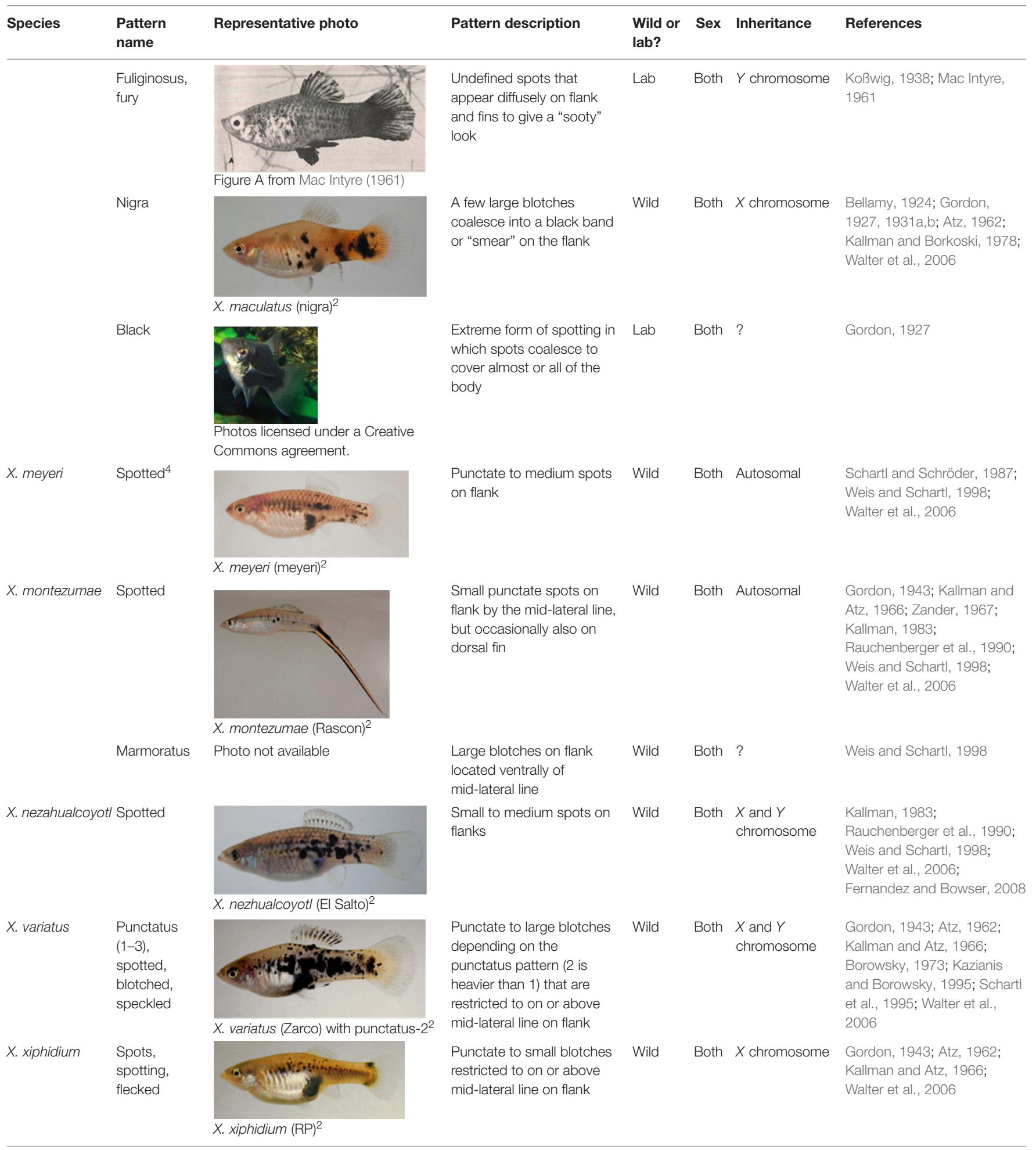

Patterns are listed by species with name of the pattern in published literature, a brief description and representative photo, whether the pattern exists in the wild, the sex that the it primarily occurs in, and the mode of genetic inheritance. 1. Creative commons photos licensed under the following agreement: https://creativecommons. org/licenses/by-sa/3.0/legalcode. 2. Images provided by the Xiphophorus Stock Center at Texas State University (Walter et al., 2006). 3. The spotted pattern has not been observed in X. couchianus since 1943. This species is extinct in the wild (Walter et al., 2006). 4. X. meyeri also exhibits a spotted pattern. The cell types have been considered intermediate between micro- and macromelanophores (Schartl and Schröder, 1987; Weis and Schartl, 1998) and as macromelanophores (Walter et al., 2006), so it is tentatively included in this review. 


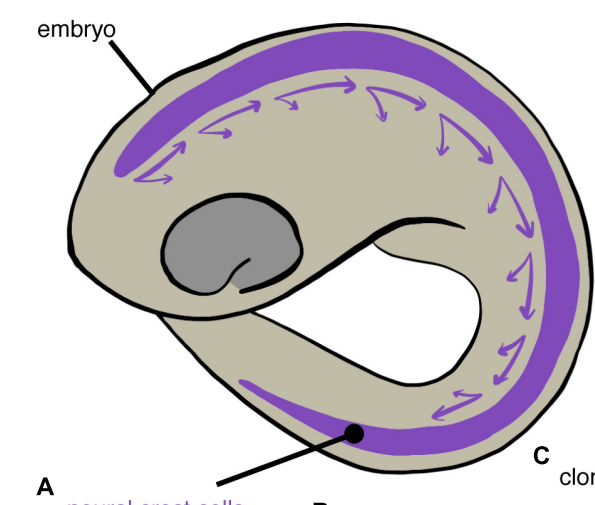

A

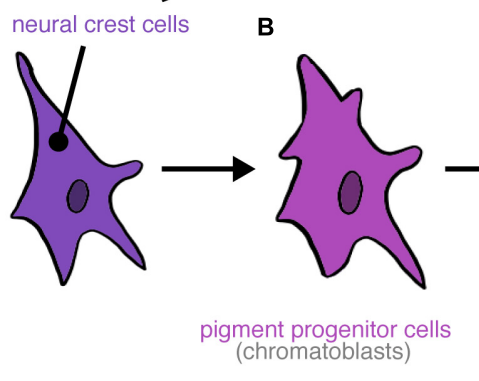

clonal division

micromelanophore progenitor cells

micromelanophores
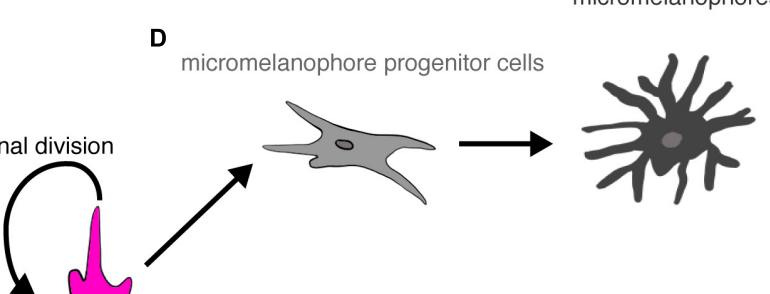

(chromatoblasts) melanophore progenitor cells
(melanoblasts)

macromelanophore progenitor cells

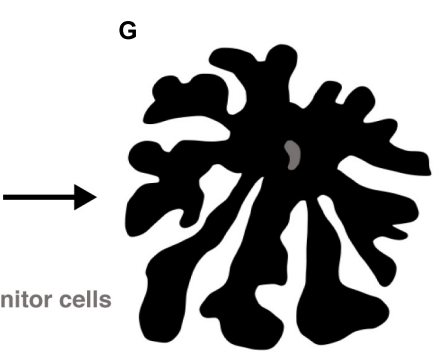

macromelanophores

FIGURE 3 | Differentiation of poeciliid melanophore cells. Neural crest cells (A) migrate in a ventral-posterior direction. They differentiate into pigment progenitor cells (B) that then further differentiate into melanophore progenitor cells (C). Melanophore progenitor cells either divide clonally or terminally differentiate into micromelanophore (D) or macromelanophore progenitor cells (F), which differentiate terminally into micromelanophores (E) or macromelanophores (G), respectively.

thicker and more branched dendritic arms (Gordon, 1931b; Regan, 1961; Vielkind, 1976; Anders et al., 1984). Because they also contain higher numbers of melanosomes, organelles that synthesize and store melanin, macromelanophore spots appear intensely pigmented (Gordon, 1931b; Regan, 1961; Vielkind, 1976; Anders et al., 1984). When G. holbrooki skin is treated with adrenaline, micromelanophores aggregate their melanosomes so skin appears lighter, whereas melanosomes in macromelanophores do not move and remain distributed so spots stay dark (Kottler et al., 2020). This difference in adrenaline response suggests that some function of melanosome regulation is altered in macromelanophores (Kottler et al., 2020). Macromelanophores can inhibit differentiation and initiate destruction of micromelanophores, but not other pigment cell types (Gordon, 1928; Schmidt, 1978). Since destruction does not require direct cell contact, macromelanophores seem to be releasing an unidentified diffusible factor that specifically targets and eliminates micromelanophores (Schmidt, 1978). The function of this destruction is unknown, although it may serve to amplify the pattern as a visual signal by creating a halo effect around the spots (Schmidt, 1978; Vielkind et al., 1982).

\section{Developmental Timeline}

Poeciliid growth rate and age of sexual maturation is strongly influenced by environmental factors (Meffe and Snelson, 1989), so we describe development in terms of sexual maturation rather than time. Unspotted morphs are born without spots and remain unspotted for their entire life (Schröder, 1964; Angus, 1983). In the wild, poeciliids are born unspotted; spots often appear as secondary sexual characteristics begin to develop, such as the gonopodium in immature males, but the melanic side-spotting pattern is not fully established until after the fish is sexually mature, after which it can increase with age in some species (Bellamy, 1924, 1928; Myers, 1925; Gordon, 1931b; Regan, 1961; Atz, 1962; Kallman and Atz, 1966; Kallman, 1971; Menzel and Darnell, 1973; Angus, 1983; Martin, 1984; Franck et al., 1998; Angus et al., 1999; Meyer et al., 2006; Gutiérrez and García, 2007). For some spotted or all-black laboratory strains, spotted morphs can be born unspotted or spotted and either develop into spotted or completely black morphs after sexual maturity (Schröder, 1964; Angus, 1983).

\section{ECOLOGY}

\section{Frequency}

For poeciliid species in which a melanic side-spotting pattern has been identified, the spotted morph is not present in every population (Gordon, 1948; Gordon and Gordon, 1957; Kallman, 1971; Martin, 1984; Horth, 2004; Culumber et al., 2014). When 
present, the frequency of spotted individuals varies depending on the population and species. In wild populations within their native range, spotted patterns ranged from a frequency of $<0.5$ to $28 \%$ of individuals in Xiphophorus maculatus, X. helleri, X. variatus, X. cortezi, G. holbrooki, Phalloceros caudimaculatus, and Poecilia mexicana (Gordon, 1943, 1948; Gordon and Gordon, 1957; Regan, 1961; Kallman, 1971; Snelson et al., 1986; Karplus and Algom, 1996; Horth, 2004; Gutiérrez and García, 2007; Culumber et al., 2014). Rarely, extreme populations occur with higher frequencies of spotted morphs ranging from 40 to over $70 \%$, as seen in X. cortezi, X. variatus, and X. xiphidium (Gordon, 1943; Kallman, 1971). Frequencies were often determined from a small subset of populations, and thus further sampling is required to understand frequency distributions for melanic side-spotting patterns across the entire native range of a species. Some invasive populations of Poecilia latipinna and Phalloceros caudimaculatus also exhibit frequencies $>50 \%$; however, these populations were founded by black or spotted individuals, which may partially explain the pattern's maintenance at a higher frequency (Nelson, 1983; McDowall, 1999; McNeil and Wilson, 2008; Petrescu-Mag et al., 2008; Koutsikos et al., 2017). Future comparisons of lowfrequency and high-frequency populations may be interesting to investigate how population-level differences affect the frequency and maintenance of spotted morphs within a species.

Melanic side-spotting patterns likely arose through random, spontaneous mutations in the pigmentation pathway. Spontaneous mutations can maintain novel phenotypes at low frequencies within populations if the mutations occur at a similar or higher rate than they are selected out of a population (Gordon and Gordon, 1957; Angus, 1983; Horth, 2006; Gutiérrez and García, 2007); however, spontaneous mutation rates are very low, and the frequencies seen in most poeciliid populations would require an improbably high mutation rate, suggesting the wide taxonomic distribution and persistence of poeciliid side-spotting is instead maintained by other processes (Huxley, 1955; Horth, 2006; Gray and McKinnon, 2007; Forsman et al., 2008; McKinnon and Pierotti, 2010). Furthermore, melanic side-spotting patterns appear to be evolutionarily stable, as macromelanophore-based patterns have possibly existed within poeciliid species for millions of years (Kazianis and Borowsky, 1995). Frequency of spotted morphs often varies seasonally and annually by population, but ultimately stabilizes around a mean over time, indicating that the pattern is an evolutionarily stable phenotype (Gordon, 1943; Gordon and Gordon, 1957; Horth and Panayotova, 2012). Since melanic side-spotting persists stably across populations and species, various molecular constraints (e.g., pleiotropy) and selective pressures (e.g., predation) likely act upon these patterns and their correlated traits to maintain them at a low frequency in the population (Gordon and Gordon, 1957; Horth, 2004), and those that have been identified in the literature are reviewed in the following sections.

\section{Life History Traits}

Life history traits are important components of fitness, so differences between morphs reflect variation in the trade-offs as well as molecular, ecological, and evolutionary constraints that govern morph life history strategies, which in turn affect the frequency and maintenance of melanic side-spotting patterns. Unspotted and spotted female Poecilia sphenops have similar gestation times, regardless of the sire's pattern (Schröder, 1964). Although most G. holbrooki broods have equal sex ratios, some male-biased broods sired by spotted males have been observed (Horth, 2006). The spotted pattern locus could contain or be linked to a selfish gene element that directly or indirectly drives the production of spotted males, which would maintain the morph in some populations. Further research into brood sex ratios is required across populations and species. Other reproductive traits like fecundity, brood size, neonate size at birth, and energy investment during gestation by females have not been systematically investigated. Xiphophorus males with heavier pigmentation often have reduced survival (Koßwig, 1927; Mac Intyre, 1961), which could reflect a fitness disadvantage that drives down the frequency of spotted morphs. In G. holbrooki, spotted males are larger than unspotted males, which could give spotted males a dominance or mating advantage that contributes to the maintenance of this polymorphism (Martin, 1977; Horth et al., 2010; Culumber et al., 2018). However, this trend cannot be generalized to every population, as temperature-sensitive siblings of the same genotype but different phenotype were the same size (Horth, 2003), or to every species, since X. helleri morphs did not differ in body mass (Meyer et al., 2006). Although feeding behavior does not differ between morph juveniles in G. holbrooki (Culumber et al., 2018), other correlated physiological (e.g., growth rate) or behavioral (e.g., food competition) traits could still underlie the increased size of spotted males (Martin, 1977; Culumber et al., 2018), while also explaining why this size difference is not a general trait across populations and species. Further research into morph trade-offs among life history traits is required.

Life history traits do not vary due to genetic and physiological differences alone; variation in social and physical environment also influences these traits, so each morph's life history strategy may only be apparent in certain conditions. For example, different frequencies of spotted and unspotted morphs alter the social environment, as the likelihood of encountering and interacting with each morph will also be different. Juvenile body condition in G. holbrooki was better when individuals were raised with a preponderance of the opposite morph, which indicates negative frequency-dependent selection (Culumber et al., 2018). Unspotted juveniles were affected to a greater degree, so morphs do seem to have underlying genetic or physiological differences that shape this trait (Culumber et al., 2018). Survival rates also differed based on the frequency of the spotted morph in G. holbrooki (Horth and Travis, 2002). When spotted males were uncommon, they survived better than unspotted males; however, as frequency of spotted males increased, their survival decreased to the same level as unspotted males (Horth and Travis, 2002; Horth, 2004). The spotted morph thus seems to have a survival advantage when uncommon, again indicating negative frequency-dependent selection. Furthermore, higher frequencies of spotted males led to higher mortality of juveniles and females (Horth and Travis, 2002), which can lower a population's reproductive capacity. Altered behavior in the presence of spotted males is hypothesized to drive this 
lower survival (Horth and Travis, 2002). For example, juvenile feeding was lower in the presence of spotted males compared to unspotted males (Culumber et al., 2018). The effect of other social environmental factors like density or sex ratio and of physical environmental factors on morph life history traits remains to be investigated across species.

\section{Predation}

Predation is a major selective pressure on animal color patterns (rev.: Endler, 1988). Studies have found that predators prefer unspotted over spotted poeciliid morphs, which may contribute to a selective survival advantage for melanic sidespotting patterns. Pike topminnow (Belonesox belizanus) ate more unspotted than spotted $X$. helleri and aimed more hunting behaviors toward unspotted model fish than spotted (Dürr, 1996 and Becker, 1997 in: Franck et al., 2001). Similarly, sunfish (Lepomis sp.) ate more unspotted than spotted G. holbrooki (Martin, 1977; Bonner, 1980 in: Martin, 1986), while both dragonfly naiads (Libellulid sp.) and crayfish (Procambarus sp.) tended to eat the unspotted morph first (Horth, 2004).

Predation is hypothesized to maintain melanic side-spotting patterns at low frequencies in poeciliid populations through negative frequency-dependent selection (Gordon and Gordon, 1957; Martin, 1977; Horth, 2004). At a low frequency of spotted G. holbrooki, Largemouth Bass (Micropterus salmoides) ate more unspotted males (Horth, 2004). This preference disappeared when the bass had access to a higher frequency of spotted males, indicating that the spotted morph only has a selective survival advantage when it is uncommon (Horth, 2004). A lack of preference by bass when the morphs were equally present (Humphrey, 2019) could be because the spotted morph frequency was above a selection threshold for these predators. Modeling negative frequency-dependent predation of G. holbrooki morphs confirmed its role in stabilizing the pattern polymorphism in populations (Horth and Panayotova, 2012).

This advantage at low frequencies could result from predators using a search image (Endler, 1988), in which they seek unspotted fish as their major prey and overlook or ignore spotted fish because they are not a common and reliable food source. When the spotted morph becomes more common, the predators adjust their search images to include them, and the former advantage disappears (Horth, 2004). Alternatively, spotted morphs could have an advantage due to other correlated traits that have not yet been identified, such as anti-predator behaviors (Horth, 2004). In a preliminary experiment, spotted and unspotted $G$. holbrooki males did not differ in their response to predator odorants (Kraft, 2016). Both morphs also exhibited similar decreases in mating behavior and increases in freezing behavior when a restrained Largemouth Bass was present (Humphrey, 2019). Although G. holbrooki morphs from a single population do not appear to exhibit differences in anti-predator behavior, this result may differ by population, poeciliid species, and predator species. Crypsis may be more important in altering predation rate. Black mollies prefer shoals that were against a black background over shoals against a white background, suggesting that background matching is important for poeciliid color morphs (Bradner and McRobert, 2001a), but crypsis has not been studied in relation to the melanic side-spotting pattern.

\section{Physical Environment}

If environmental factors differentially affect the fitness of spotted and unspotted morphs, then frequency of the melanic side-spotting pattern may vary temporally and spatially with these factors (Gordon and Gordon, 1957; Horth and Travis, 2002). Some $X$. helleri live in seasonally variable streams that are clear in the dry season and turbid in the rainy season, while $P$. mexicana populations are found in both non-sulfidic springs with clear water and in sulfidic springs with cloudy water that creates a white background (Franck et al., 2001; Culumber et al., 2014). Both unspotted X. helleri females in clear water and unspotted $P$. mexicana females from nonsulfidic springs preferred unspotted social partners (Franck et al., 2001; Culumber et al., 2014). In turbid water, unspotted female $X$. helleri switched their preference to spotted social partners, while unspotted female $P$. mexicana from cloudy sulfidic springs showed no preference between morphs (Franck et al., 2001; Culumber et al., 2014). In both species, spotted morphs preferred spotted social partners (Franck et al., 2001; Culumber et al., 2014). Spotted fish therefore seem to have a social advantage in low visibility conditions, most likely driven by the increased visibility of spotted individuals compared to unspotted (Franck et al., 2001). Since spotted P. mexicana were only obtained for sulfidic springs, these populations may alternatively differ in genetic preferences (Culumber et al., 2014). Selective advantage of the spotted morph thus seems to vary spatially and temporally depending on environmental conditions (Franck et al., 2001), and could explain different frequencies of the pattern across species' populations.

Environmental factors can also affect the expression of melanic side-spotting patterns (Regan, 1961; Schröder, 1964; Anders and Klinke, 1965). For example, a small number of populations of $G$. holbrooki and P. latipinna are temperaturesensitive, exhibiting greater expression of the spotted pattern at low water temperatures experienced during the winter ( $<22^{\circ}$ C; Schröder, 1964; Angus, 1983, 1989; Angus et al., 1999; Horth, 2006). In simulated population models of G. holbrooki, temperature affected population frequency of the spotted morph both seasonally and long-term under different climate change scenarios (Horth and Panayotova, 2012; Panayotova and Horth, 2018). Variation in temporal expression of the spotted pattern could then influence how and when selective pressures affect this morph's fitness. A fish born in the spring will be unspotted, then mature and reproduce during the summer, all before winter temperatures induce expression of the spotted phenotype (Angus, 1983). The spotted pattern gene(s) would thus be inherited and maintained in the population regardless of fitness costs later in the fish's life because natural selection did not act upon the phenotype before the bulk of reproduction took place (Angus, 1983). Alternatively, the spotted and unspotted morphs may differ in fitness in warm and cool waters, possibly through other correlated traits, which would favor inducible phenotypic expression (Horth, 2003; Meyer et al., 2006). The effect of other physical factors on pattern expression and morph fitness remains 
unexplored, including oxygen conditions, salinity, precipitation, seasonal flooding and drying out of areas (hydroperiod), habitat fragmentation, vegetative cover, food availability, ultraviolet light exposure, behavioral thermoregulation, and parasitism (Gordon and Gordon, 1957; Schröder, 1964; Borowsky, 1973; Nelson and Planes, 1993; Meyer et al., 2006; Ducrest et al., 2008; PetrescuMag et al., 2008; Horth et al., 2013; San-Jose and Roulin, 2018).

\section{SOCIAL BEHAVIOR}

\section{Social Conflicts: Aggression and Dominance}

Behavioral studies on the melanic side-spotting pattern exhibit a strong species bias to Eastern Mosquitofish (G. holbrooki), likely due to its widespread distribution and accessibility. Behavioral differences between G. holbrooki morphs are easily observable, and had already been noted in wild populations a century ago (Myers, 1925), which likely further sparked the multitude of studies aimed at understanding spotted morph behavior. Below we present trends in social behavior, but we advise caution in generalizing these trends and encourage further research into behaviors correlated with the melanic side-spotting pattern in other poeciliid species.

Melanin-based color patterns are associated with higher aggression, bold behavior, and social dominance across taxa (revs.: Ducrest et al., 2008; McKinnon and Pierotti, 2010; San-Jose and Roulin, 2018). In G. holbrooki, one morph is not inherently more aggressive than the other; rather, male G. holbrooki morphs alter their behavior depending on their social partner and the composition of their social group (Martin, 1977; Horth, 2003; Kraft et al., 2018). In same-morph groups, unspotted males exhibited higher aggression toward each other than spotted males did (Martin, 1977). In mixed-morph groups, unspotted and spotted males directed similar levels of aggression toward unspotted males, but unspotted males directed less aggression back to spotted males (Martin, 1977; Horth, 2003; Kraft et al., 2018). Spotted male dominance over unspotted males thus seems to be driven by behavioral changes of unspotted males (Martin, 1977; Horth, 2003; Kraft, 2016). A dominance advantage for spotted males could maintain the pattern in populations if it also confers a fitness advantage. However, this correlation may not be present in all poeciliids. Within male $X$. helleri dyads, neither unspotted nor spotted males achieved dominance over the other (Franck et al., 2001). As well, spotted X. variatus were more shy in new environments (Culumber, 2016), rather than bold as would be expected of dominant fish.

Unspotted G. holbrooki juveniles exhibited more submissive behaviors toward spotted adults than unspotted adults, whereas spotted juveniles did not change their behavior based on color composition of the social group (Kraft et al., 2018). Unyielding dominance behaviors by spotted males could be a tactic to win more social conflicts against unspotted males, as the unspotted males would be more likely to switch to submissive behaviors and thus lose. This behavioral inflexibility may also confer stress resistance, which is typically a fitness advantage (rev.: Wingfield and Sapolsky, 2003), as the spotted morph would maintain their normal behavior in a variety of contexts. For example, spotted X. variatus exhibited greater behavioral resistance to stress than unspotted morphs (Culumber, 2016). Alternatively, this inflexibility may be a fitness disadvantage if spotted morphs do not avoid stressful or costly conflicts.

\section{Precopulatory Sexual Selection: Mating and Sexual Activity}

Findings conflict on whether morphs differ in sexual behavior and in precopulatory sexual selection by females. Where differences do exist, they seem to be influenced by population, species, morph frequency, experience, and environmental factors. (The reader interested in larger patterns may safely skip to the next section, "Social Groups"). In G. holbrooki, spotted males sometimes exhibited lower sexual activity than unspotted males (Nelson and Planes, 1993; Kraft et al., 2018), no difference (Martin, 1977; Karplus and Algom, 1996), or higher sexual activity (Martin, 1977; Karplus and Algom, 1996; Horth, 2003; Humphrey, 2019; Culumber et al., 2020). Results may depend on which specific sexual behaviors are measured. For example, Karplus and Algom (1996) found that morphs did not differ in time spent following females but spotted males were more likely to associate with females and interfere with other individuals' sexual interactions. These conflicting results may also be a function of different densities and morph frequencies (Martin, 1977), or selective pressures particular to the origin population that strongly influence the presence and direction of the pigmentation-behavior correlation.

Female behavior toward males can influence mating success for both courtship and coercive mating strategies in poeciliids (Bisazza et al., 2001). Female preferences for these morphs vary widely, most likely because responses are shaped by female morph identity, population, experience, and social context. For example, female G. holbrooki either directed more aggression toward spotted males and avoided them (Martin, 1977; Taylor et al., 1996), or were equally aggressive to both morphs (Horth, 2003). Female G. holbrooki preferred free-swimming unspotted males (Nelson and Planes, 1993; Taylor et al., 1996; Horth, 2003), but showed no preference when a barrier separated the sexes (Martin, 1986; Nelson and Planes, 1993) and have even preferred spotted and black stationary models (Gould et al., 1999). Even if G. holbrooki females have an innate preference for spotted males, other traits that are correlated with the melanic sidespotting pattern, such as sexual activity, may be more important in setting these preferences in the wild. Local environmental selective pressures may also strongly influence morph preferences because female preferences from different origin populations or environmental conditions differ in several species: G. holbrooki (Bisazza and Pilastro, 2000; Bisazza et al., 2001), X. helleri (Franck et al., 2001), and P. mexicana (Culumber et al., 2014). Finally, it is unknown whether females prefer traits that only sometimes correlate with the melanic side-spotting pattern instead of the pattern itself, which may also explain these conflicting results.

Higher sexual activity or female preference for a color morph could lead to higher mating success and thus higher reproductive fitness, which would contribute to that morph's maintenance in 
a population (Martin, 1977). In contrast, higher sexual activity could be disadvantageous if the males over-harass and stress females, leading to increased female mortality or decreased reproductive output (Horth and Travis, 2002). G. holbrooki females paired with size-matched spotted and unspotted males produced broods with frequencies of each phenotype that matched the expectation that neither morph had a mating advantage that translated into a fitness advantage (Horth et al., 2010); however, reproductive fitness may depend on morph frequencies in a population and should still be investigated. To our knowledge, postcopulatory sexual selection has not been studied in species with side-spotted morphs.

\section{Social Groups}

Spotted and unspotted morphs do not encounter and interact with color morphs and sexes at similar rates. Each morph may thus have a different social group, which in turn affects social dynamics. Both G. holbrooki morphs interacted with the same number of unspotted males, but spotted males had more social partners and more interactions with females than unspotted males in the lab and in the wild (Kraft et al., 2016). Both white and black mollies preferred phenotypically similar shoal mates (McRobert and Bradner, 1998; Bradner and McRobert, 2001b). Although white and black mollies are the result of domestication and hybridization among Poecilia species (McRobert and Bradner, 1998; Bradner and McRobert, 2001b), black mollies represent an extreme form of spotting and may still provide some insights, but these preferences should still be investigated in Poecilia spotted morphs. In clear water, unspotted and spotted female $X$. helleri also preferred phenotypically similar schools (Franck et al., 2001). Asymmetric social interactions between morphs could lead to assortative schooling, influencing dominance and mating dynamics, which would in turn affect morph fitness. However, social groups are also influenced by experience, as both black and white mollies preferred to shoal with the morph with which they were raised over phenotypically similar fish (Ledesma and McRobert, 2008). Given that spotted morphs are usually uncommon, both morphs may prefer to shoal with the familiar and common unspotted morph, and thus assortative schooling and mating may not occur in the wild. To our knowledge, social interactions with heterospecific individuals have not yet been investigated.

\section{GENETICS}

\section{Modes of Inheritance}

The melanic side-spotting pattern is always a genetically dominant trait (Gordon, 1927, 1937; Fraser and Gordon, 1929; Gordon and Smith, 1938; Gordon and Gordon, 1957; Atz, 1962; Schröder, 1964; Zander, 1965; Kallman and Atz, 1966; Kallman, 1971; Angus, 1983, 1989; Horth, 2006; Gutiérrez and García, 2007). Long-term persistence of a dominant trait indicates that multiple positive and negative selective pressures likely act upon the pattern and its correlated traits (Gordon and Gordon, 1957). Mode of inheritance differs across species and for each specific melanic side-spotting pattern (Table 1). In some species, the pattern is controlled by one or more autosomal genes (Atz, 1962; Schröder, 1964; Zander, 1965; Kallman and Atz, 1966; Kallman, 1971; Angus, 1983). In others, the patterns are linked to a sex chromosome (Gordon, 1927, 1946, 1951; Fraser and Gordon, 1929; Bellamy, 1936; Regan, 1961; Anders et al., 1973; Kallman, 1983; Angus, 1989; Horth, 2006; Fernandez and Bowser, 2008). Sex-linkage may evolve in certain species through sexually antagonistic selection (Kottler and Schartl, 2018); the melanic side-spotting pattern or its correlated traits may be advantageous to male fitness but disadvantageous to female fitness, resulting in strong selective pressure for pattern expression to be greater in males than females (Kottler and Schartl, 2018). For melanic side-spotting patterns that are primarily expressed in males, spotted females are rare (Fraser and Gordon, 1929; Gordon, 1947; Snelson et al., 1986). These spotted females could arise through sex chromosome crossover, which is also a rare event (Kallman, 1965). Alternatively, these exceptional females have atypical sex determination and are genetically male, as was likely the case for a rare spotted female G. holbrooki (Snelson et al., 1986; Angus, 1989).

\section{Polygenic Control}

The melanic side-spotting pattern is heritable, controlled primarily by genetics (Koßwig, 1929). At least one gene exists that controls the presence of macromelanophore pigmentation, and this locus has been dubbed the Macromelanophore-determining locus or Mdl (Vielkind, 1976; Vielkind et al., 1976, 1982; Anders and Anders, 1978; Weis and Schartl, 1998; Gutbrod and Schartl, 1999). In some species, degree of pigmentation expression may be the result of gene dosage, the number of pigmentation alleles inherited (Schröder, 1964; Kallman, 1971; Gutiérrez and García, 2007, 2011). In others, specific melanic side-spotting patterns can vary in amount and size of spots, in developmental timing of expression, and in location of spots on the fish's body (Table 1), indicating that spotting patterns have different genetic origins and/or that additional regulatory genes play a role in determining pattern expression (Gordon, 1931b; Kallman and Atz, 1966). Hybridizations across populations and species of Xiphophorus result in altered pattern expression, usually leading to heavier pigmentation and sometimes to melanomas (Koßwig, 1929; Gordon and Smith, 1938; Gordon, 1951; Atz, 1962; Anders et al., 1973). This altered pigmentation is the result of mismatches between the pattern genes of one population or species and the regulatory genes of another, indicating that these patterns are under polygenic control (Gordon and Smith, 1938; Gordon, 1951; Atz, 1962; Anders et al., 1973). The number of genes and the location of the loci involved may differ across poeciliid populations and species (Anders et al., 1973). One to a few genes control the pattern in some species (Schröder, 1964; Kallman, 1971; Horth, 2006), while others involve multiple genes across chromosomes interacting together (Kallman and Atz, 1966; Anders et al., 1973; Borowsky, 1973).

\section{Candidate Genes for Melanic Spotting Patterns}

Most genetic work on macromelanophore pigmentation patterns has been conducted in the Xiphophorus melanoma model. 
Knowledge about the genetics underlying these patterns outside of Xiphophorus is practically non-existent with the notable exception of G. holbrooki (Kottler and Schartl, 2018; Kottler et al., 2020). At this time, no gene has been explicitly identified as the macromelanophore-determining gene in poeciliids (Kottler et al., 2020). Candidate genes for the development and regulation of melanomas are reviewed elsewhere (rev.: Schartl, 2008; Schartl and Walter, 2016), so we will focus on the genetic mechanisms that appear to be related to the presence and expression of melanic side-spotting patterns.

The presence of macromelanophores is controlled by the $M d l$ in X. maculatus and in G. holbrooki (Vielkind, 1976; Vielkind et al., 1976, 1982; Anders and Anders, 1978; Weis and Schartl, 1998; Gutbrod and Schartl, 1999; Kottler et al., 2020). This locus is hypothesized to consist of co-dominant alleles, including macromelanophore and other regulatory genes (Kallman and Atz, 1966; Anders et al., 1973; Vielkind and Vielkind, 1982; Weis and Schartl, 1998). The "macromelanophore gene(s)" that control the presence or absence of the melanic side-spotting pattern likely act on the melanophore progenitor cells, affecting whether they are assigned to the micro- or macromelanophore fate (Vielkind and Vielkind, 1982). In G. holbrooki, the presence of the spotted pattern was linked to an allele on the $Y$ chromosome for GIPC1 (GIPC PDZ domain containing family member 1), which functions in vesicle trafficking and sorting proteins to melanosomes for pigment synthesis (Liu et al., 2001; Kottler et al., 2020); however, its specific function in the melanic sidespotting pattern has not yet been determined. Because of its role in macromelanophore proliferation during melanoma formation, the Xiphophorus "macromelanophore gene" was thought to be Xmrk (Xiphophorus receptor tyrosine kinase), a homolog of epidermal growth factor receptor b (Wittbrodt et al., 1989; Schartl, 2008). However, Xmrk is found in species both with and without the spotting pattern, so it does not define the pattern's presence (Weis and Schartl, 1998; Schartl, 2008). At this time, Xmrk's known relation to spotting is as a marker of $M d l$, although it may still have an undefined function related to pattern expression; Xmrk has been proposed to control the migration of pigment progenitor cells from the neural crest and to inhibit certain cell lines from differentiating into macromelanophores (Adam et al., 1991; Weis and Schartl, 1998; Schartl, 2008).

Regulatory genes linked to the $M d l$ appear to control the type of melanic side-spotting pattern and the pattern's location on the fish's flank, as these features do not change with hybridization in Xiphophorus (Anders and Anders, 1978; Schartl, 1990). Non-linked regulatory genes appear to control the number of melanophore progenitor cells that differentiate into macromelanophores, the developmental timing of macromelanophore appearance, as well as the size and number of spots in Xiphophorus (Anders et al., 1973, 1984; Vielkind et al., 1976; Anders and Anders, 1978; Vielkind and Vielkind, 1982; Gutbrod and Schartl, 1999). The identities of these regulatory genes are still unknown, but some studies have identified candidates for the Xiphophorus autosomal locus $R($ Diff), named for "regulatory or differentiation," that appears to control the terminal differentiation of melanophore progenitor cells into macromelanophores (Vielkind, 1976; Vielkind and Vielkind, 1982; Vielkind et al., 1982), and may have additional functions in pattern expression (Schartl, 2008). Although not yet investigated for the melanic sidespotting pattern, 22 candidates for melanoma regulation were identified as part of the $R($ Diff) region in Xiphophorus hybrids with the spotted-dorsal fin pattern (for a detailed description, see: Lu et al., 2017). Many of the identified genes have known functions that could affect pattern expression and other physiological or behavioral traits, including cell cycle regulation, cell differentiation, cell signaling, cell migration, cell structure and adhesion, and transcription and translation factors (Lu et al., 2017).

Few candidate genes have been identified that are linked to melanic side-spotting patterns, and their specific functions in patterning or in phenotypic correlations are still unknown. Since a variety of molecular systems can regulate both pigmentation and other traits (e.g., melanocortins, monoamines; see: section "Mechanisms of Pigmentation-Phenotype Correlation"), we suggest that parallel research studies be conducted to identify each gene system's contribution to the pattern's expression and to its correlation with other traits. Nonprotein-coding mechanisms that affect gene expression and protein function should also be considered, including epigenetic regulation, gene promoters, non-coding RNAs, and post-translational modifications (Ducrest et al., 2008; Kottler and Schartl, 2018).

\section{Temperature-Sensitivity Mechanism}

Gene $\mathrm{x}$ environment interactions can affect presence and expression of the melanic side-spotting pattern (Vielkind and Vielkind, 1982). In a subset of G. holbrooki and P. latipinna populations, the pattern is temperature-sensitive with reduced penetrance at higher temperatures (Schröder, 1964; Angus, 1983, 1989; Angus et al., 1999; Horth, 2006). Temperaturesensitivity has not been identified in many populations or in other species, although expression of the spotted-dorsal fin pattern in Xiphophorus hybrids also exhibited incomplete penetrance at high water temperatures (Perlmutter and Potter, 1988). We propose a few evolutionary hypotheses for why temperature-sensitivity is limited to only a subset of populations within a species. First, the constitutively expressed and temperature-sensitive melanic side-spotting patterns may have evolved independently within a species through different genes (Angus, 1989). Second, these populations share the same melanic side-spotting pattern locus but have different alleles, only some of which confer temperaturesensitivity (Angus, 1989). For example, a hypothetical protein important for macromelanophore determination might function constitutively in one population, but a mutation in that protein could have evolved in another population that makes its splice variation or tertiary structure temperaturesensitive. Finally, temperature-sensitivity could be an additional regulatory gene or locus that has evolved independently in a subset of populations.

Temperature-sensitivity appears to be genetically controlled, as it was inherited paternally in G. holbrooki (Horth, 2006). 
The molecular mechanism for temperature-sensitivity could be either in the $M d l$ or in regulatory loci. Molecular interactions, gene expression, and protein instability generally increase with temperature. G. holbrooki and P. latipinna show an unusual trend in the opposite direction, similar to mammals that express a Himalayan pattern in which they are normally white but body areas exposed to low temperatures express melanin pigmentation; increased melanin synthesis via increased tyrosinase activity at low temperatures is a key mechanism for melanism in mammals (Kidson and Fabian, 1981; Kwon et al., 1989). Angus (1989) found tyrosinase activity in temperaturesensitive $P$. latipinna was elevated at higher temperatures when expression of the spotting pattern was weak; therefore, tyrosinase activity does not seem to be the temperature-sensitivity mechanism. In spotted-dorsal fin Xiphophorus hybrids, higher temperatures led to multi-vesiculated macromelanophores, which Perlmutter and Potter (1988) suggest is due to inhibition of melanin synthesis within vesicles. Alternatively, temperaturesensitivity could result from failure to transport tyrosinase to the melanosomes in these pigment cells (hence the empty vesicles), as retention of tyrosinase by the endoplasmic reticulum was higher at elevated temperatures in himalayan mouse cells (Halaban et al., 2000). Mutations that lead to increased stability of tertiary protein structure at low temperatures are another potential mechanism. Finally, we should consider that temperature-sensitivity may not be due to polymorphisms in protein-coding genes; for example, temperature-sensitive epigenetic regulation of pigmentation gene expression is possible. A shared temperature-sensitive molecular system could lead to the correlated expression of the melanic side-spotting pattern and other traits, as seen in a temperaturesensitive population of $G$. holbrooki. Males of the same genotype were exposed to different temperatures, so they were either unspotted or spotted, and these expressed patterns correlated with behavioral differences (Horth, 2003).

\section{EVOLUTIONARY ORIGINS}

Although melanic side-spotting patterns appear across Poeciliidae, the differences in inheritance and pattern features within and across species suggests that many of these patterns have different genetic mechanisms (Gordon, 1931b; Kallman and Atz, 1966). It is not clear at this time whether melanic side-spotting patterns arose through homologous, convergent, and/or parallel evolution within Poeciliidae, within specific genera, or even within species.

Here, we consider the possible evolutionary origins of melanic side-spotting patterns using the genus Xiphophorus as an example. First, pigmentation loci may have evolved independently in some species while others share a common ancestor. For example, the sex chromosomes of $X$. variatus and $X$. maculatus are homologous so they may share an ancestral spotted pattern, but the $X$. helleri autosome is not homologous with those two, and its spotted pattern may have evolved independently (Kallman and Atz, 1966; Schartl, 1990). Alternatively, the pattern genes were originally all on the same homologous chromosome and then translocated to another chromosome in a subset of species (Kottler and Schartl, 2018). Second, Xiphophorus may have a shared ancestral spotted pattern that was repeatedly lost in some species, which would explain why $M d l$ homologs exist in species without macromelanophore patterns (Weis and Schartl, 1998). Regulatory genes could have then evolved independently in different populations and species through parallel evolution, which would alter the development, expression, and location of the patterns (Anders et al., 1973; Vielkind and Vielkind, 1982; Schartl, 1990). Mdl on Xiphophorus sex chromosomes is linked to regions that may be hotspots for gene duplication, structural rearrangements, and recombination (Volff and Schartl, 2001), suggesting that a high incidence of parallel evolution is possible for some Xiphophorus species. Thus, a similar combination of homologous, convergent, and parallel evolution is hypothesized to explain the origin of multiple melanic side-spotting patterns in Poeciliidae.

\section{PHYSIOLOGY}

\section{Androgens}

Many endocrine and neuroendocrine substances are involved in the regulation of pigmentation, so physiological correlates are expected within morphs. Because the expression of the melanic side-spotting pattern is male-biased in some species (Angus, 1989; Horth, 2006), androgens have been hypothesized to affect the pattern's presence. Mature unspotted G. holbrooki females treated with methyl-testosterone developed male gonopodia but did not develop the spotted pattern (Angus, 1989; Horth, 2006). Although these results suggest that the pattern is sex-linked and not sex-limited in $G$. holbrooki, some caution should be applied. Methyl-testosterone is not a potent androgen in teleosts; if the pattern requires higher androgenic activity to appear in females, then 11-keto-testosterone is more likely to produce observable effects (Hishida and Kawamoto, 1970). Furthermore, secondary sexual characteristics have late life plasticity, but that does not necessarily mean that expression of the pattern also has late life plasticity. Expression of androgen receptors is often primed early in life, so testosterone may only induce pattern expression in females when applied before sexual maturity.

In species where both sexes express the melanic sidespotting pattern, males often have higher expression and heavier pigmentation (Gordon, 1927, 1951; Häussler, 1928; Bellamy, 1936; Mac Intyre, 1961; Borowsky, 1973; Angus et al., 1999; McDowall, 1999), so androgen levels are hypothesized to affect pattern variation among individuals and sexes, but circulating levels have not yet been measured in relation to initiation of spotting patterns. Individuals expressing melanin-based coloration often have higher circulating levels of sex steroids (rev.: San-Jose and Roulin, 2018), but whether differences between spotted and unspotted morphs in poeciliids exist are still unknown. Hormones often have pleiotropic effects (Ketterson and Nolan, 1999), and high levels of sex steroids are associated with higher social dominance (rev.: Oliveira et al., 2002); thus, if higher pigmentation expression in males is due to higher levels of sex steroids, then it may represent a pleiotropic mechanism for the correlation of the melanic side-spotting 
pattern and behavior in poeciliids. Alternatively, sex steroid levels are correlated to behavior as opposed to the melanic side-spotting pattern, as suggested by the "challenge hypothesis" (Wingfield, 1984; Oliveira et al., 2002). Briefly, spotted and unspotted morphs experience different social environments; if spotted morphs experience more aggressive social interactions, they might respond with higher circulating androgen levels.

\section{Metabolism and Cortisol}

Melanocortins were previously identified as a key candidate for pleiotropy between melanin-based color patterns and physiological traits. Melanocortins regulate melanin production, energy balance, and glucocorticoid release, among other traits (revs.: Ducrest et al., 2008; San-Jose and Roulin, 2018). Although spotted G. holbrooki males had higher basal cortisol levels than unspotted males, no significant difference in cortisol responses to an introduced stress (presence of a predator) was observed between morphs (Humphrey, 2019). This negative result may be a function of low sample size. To our knowledge, no study has measured other circulating hormones, such as melanocortins like $\alpha$-melanocyte stimulating hormone. Metabolic rate also does not appear to correlate with the melanic side-spotting pattern in poeciliids, as spotted and unspotted morphs of $X$. variatus and $X$. helleri did not differ in metabolic rate (Meyer et al., 2006; Culumber, 2016). Spotted morphs might have a physiological compensation mechanism that counteracts changes in metabolic rate associated with pigmentation expression, or metabolic rate may not be a major outcome of melanocortin systems.

\section{Melanoma}

Macromelanophore-based patterns in Poeciliidae have been heavily studied as a model for skin cancer, particularly in hybrid Xiphophorus species; hybridization across populations or species creates a mismatch between the pigmentation pattern genes and their regulatory genes, which results in the unregulated differentiation of macromelanophores and the formation of tumors (revs.: Anders et al., 1973, 1984; Anders and Anders, 1978; Vielkind and Vielkind, 1982; Schartl and Walter, 2016). However, melanomas have been observed in senescent individuals from natural populations of $X$. variatus and $X$. nezahualcoyotl, as well as a non-hybrid lab strain of $X$. variatus (Borowsky, 1973; Schartl et al., 1995; Fernandez and Bowser, 2008), so we will discuss the possible influence of melanomas on the evolution of melanic side-spotting patterns.

Melanoma is a potential mechanism for reducing the frequency of spotted individuals in a population (Gordon and Gordon, 1957). When malignant melanomas occur in hybrid Xiphophorus, they lower fish health and reduce survival, decreasing the fitness of spotted individuals; however, only a small proportion of these hybrid fish develop malignant melanomas, and melanomas are extremely rare in natural populations, so this disadvantage is not likely to be a general feature of this pattern (Häussler, 1928; Anders et al., 1973; Anders and Anders, 1978; Schartl, 2008); however, the rarity of melanomas in natural populations may also be a sampling artefact, as these fish are unlikely to survive and thus unlikely to be sampled. In Xiphophorus, only species with the constitutively active oncogene Xmrk develop melanomas, so not all species with macromelanophore patterns are expected to experience the melanoma fitness disadvantage (Anders and Anders, 1978; Weis and Schartl, 1998). Although, other undiscovered mutations that lead to melanoma formation in macromelanophores could potentially still exist (Fernandez and Bowser, 2008). Finally, macromelanophore patterns can potentially evolve repeatedly through mutation; if individuals with these mutations also repeatedly develop melanomas, natural selection would act to eventually include regulatory genes that prevent this deleterious side-effect, which have been found in multiple populations and species of Xiphophorus (Gordon and Gordon, 1957; Atz, 1962; Borowsky, 1973). Thus, the fitness disadvantage associated with melanomas is likely not a strong selective pressure on the melanic side-spotting pattern (Anders et al., 1973; Schartl, 2008). Melanomas also often develop later in life in both nonhybrid and hybrid Xiphophorus, weakening selection against it; selection delayed is selection denied (Gordon and Gordon, 1957; Williams, 1957; Mac Intyre, 1961; Anders et al., 1973; Schartl et al., 1995). Selective pressures that act upon the melanic sidespotting pattern before melanoma development would thus have stronger effects on the pattern's frequency in populations.

The risk of developing malignant melanomas was higher for homozygotes of $X$. maculatus with the "fuliginosus" pattern and of $X$. variatus with the "punctatus- 2 " pattern, indicating that the melanoma fitness disadvantage may be stronger in homozygotes than heterozygotes (Mac Intyre, 1961; Borowsky, 1973). If the spotted pattern has other fitness advantages, these positive selective pressures on heterozygotes may outweigh the negative effect of melanomas on homozygotes (Borowsky, 1973; Kazianis and Borowsky, 1995), and thus the pattern would be maintained in the population as a polymorphism. Higher fitness of heterozygotes for the melanic side-spotting pattern could potentially explain the evolution of sex-linkage in some poeciliid species, as only one of the sex chromosomes carries the pigmentation allele, thereby preventing melanoma (Borowsky, 1973). Alternatively, because of their correlation with heavier expression of pigmentation patterns, melanomas may be under positive selection if expression is correlated with a fitness advantage. For example, $X$. cortezi females in some populations preferred males with heavier expression of a macromelanophorebased tail spot pattern (spotted caudal) that is associated with an increased risk of melanoma (Fernandez and Morris, 2008). Melanomas enhance the preferred pattern's appearance, which could lead to its maintenance through sexual selection in some populations (Fernandez and Morris, 2008). The possible fitness advantages of melanomas have not yet been studied in relation to melanic side-spotting patterns. Other aspects of fish health have not been investigated for the melanic side-spotting pattern. Melanin has known anti-parasitic properties in poeciliids, so spotted morphs could potentially have greater resistance to parasites (Meyer et al., 2006; Horth et al., 2013). Differences in the immune system exist in other species with melanin-based pigmentation patterns (revs.: McKinnon and Pierotti, 2010; SanJose and Roulin, 2018), and thus should also be investigated for spotted and unspotted poeciliid morphs. 
TABLE 2 | Summary of traits and selective pressures investigated for melanic side-spotting pattern in poeciliid species. We briefly describe the experiment and results. Direction of effect is listed as increased (+), decreased (-), and no difference ( $)$ for the spotted morph compared to the unspotted morph.

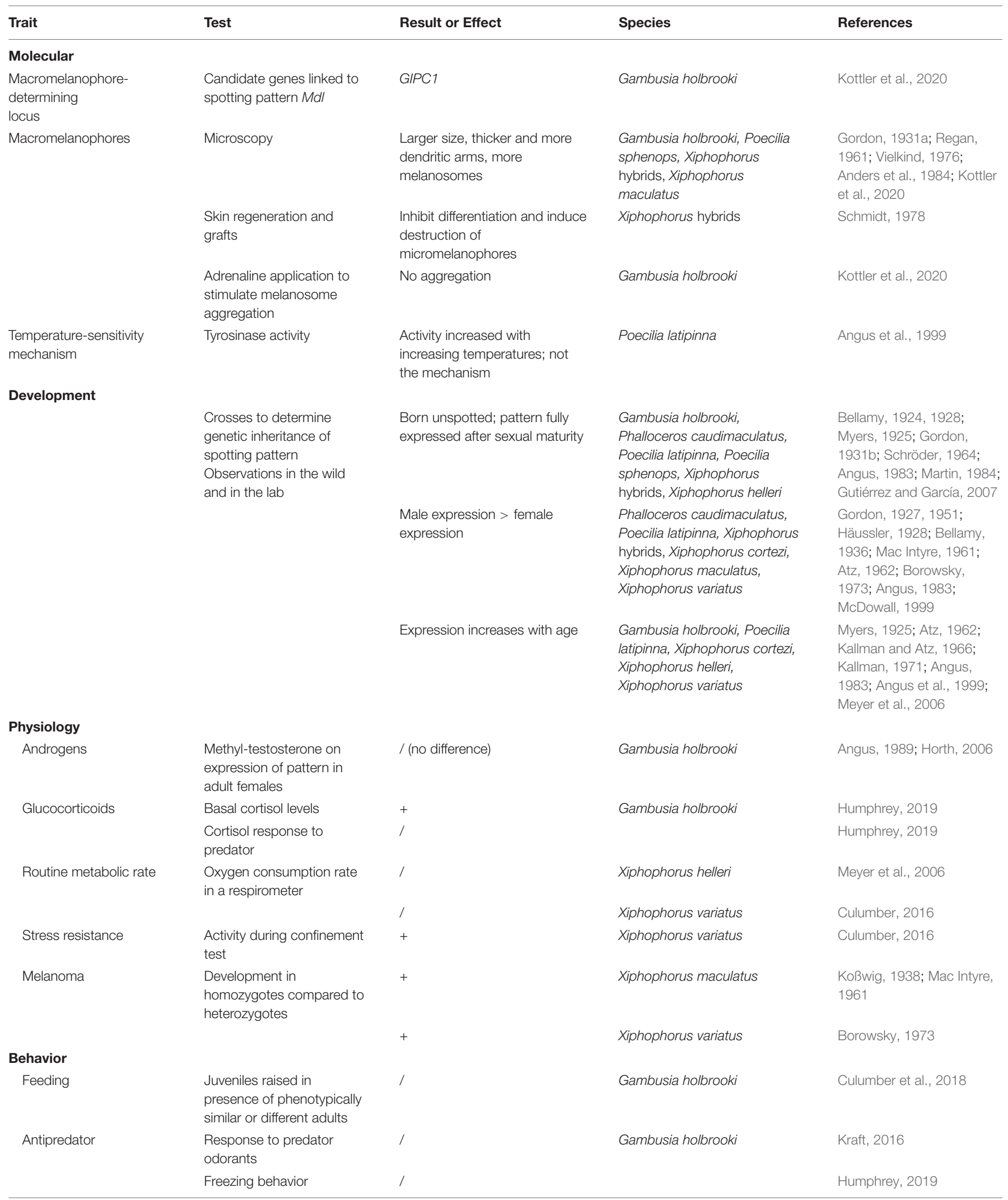


TABLE 2 | Continued

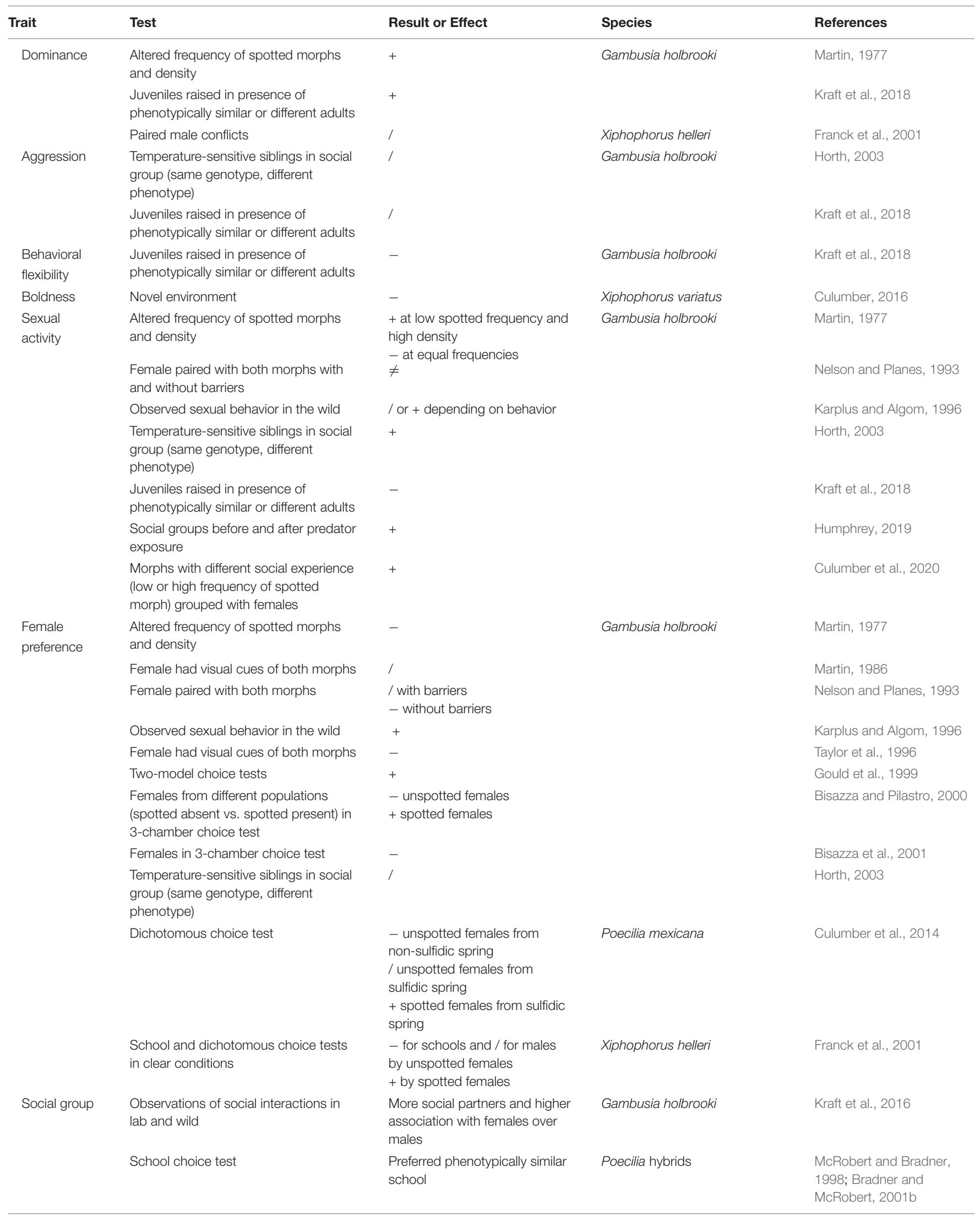


TABLE 2 | Continued

\begin{tabular}{|c|c|c|c|c|}
\hline Trait & Test & Result or Effect & Species & References \\
\hline & $\begin{array}{l}\text { School choice test based on } \\
\text { experience }\end{array}$ & $\begin{array}{l}\text { Preferred to school with familiar } \\
\text { color pattern }\end{array}$ & & $\begin{array}{l}\text { Ledesma and McRobert, } \\
2008\end{array}$ \\
\hline \multicolumn{5}{|l|}{ Life History Traits } \\
\hline Gestation & $\begin{array}{l}\text { Length of gestation for different female } \\
\text { and male morphs }\end{array}$ & / & Poecilia sphenops & Schröder, 1964 \\
\hline $\begin{array}{l}\text { Brood sex } \\
\text { ratio }\end{array}$ & $\begin{array}{l}\text { Crosses to determine genetic } \\
\text { inheritance of spotting pattern }\end{array}$ & $\begin{array}{l}\text { Usually equal sex ratios, } \\
\text { although some male-biased }\end{array}$ & Gambusia holbrooki & Horth, 2006 \\
\hline \multirow[t]{4}{*}{ Survival } & Mesocosms with varying frequency & $\begin{array}{l}\text { + at low spotted frequency } \\
\text { - at high spotted frequency }\end{array}$ & Gambusia holbrooki & Horth and Travis, 2002 \\
\hline & Field survival & / & & Horth, 2004 \\
\hline & $\begin{array}{l}\text { Crosses to determine genetic } \\
\text { inheritance of spotting pattern }\end{array}$ & - & Xiphophorus maculatus & Mac Intyre, 1961 \\
\hline & & - & Xiphophorus hybrids & Koßwig, 1927 \\
\hline \multirow[t]{3}{*}{ Body size } & Measured in nature and in the lab & + & Gambusia holbrooki & $\begin{array}{l}\text { Martin, 1977; Horth et al., } \\
2010\end{array}$ \\
\hline & $\begin{array}{l}\text { Temperature-sensitive siblings (same } \\
\text { genotype, different phenotype) }\end{array}$ & / & & Horth, 2003 \\
\hline & $\begin{array}{l}\text { Measured for same-age morphs in the } \\
\text { lab }\end{array}$ & / & Xiphoporus helleri & Meyer et al., 2006 \\
\hline $\begin{array}{l}\text { Body } \\
\text { condition }\end{array}$ & $\begin{array}{l}\text { Juveniles raised in presence of } \\
\text { phenotypically similar or different adults }\end{array}$ & + & Gambusia holbrooki & Culumber et al., 2018 \\
\hline \multicolumn{5}{|l|}{ Environment } \\
\hline \multirow[t]{6}{*}{ Predation } & Consumption by predator & - & Gambusia holbrooki & $\begin{array}{l}\text { Martin, 1977; Bonner, } 1980 \\
\text { in: Martin, } 1986\end{array}$ \\
\hline & & $\begin{array}{l}\text { + at low spotted frequency } \\
\text { - at high spotted frequency }\end{array}$ & & Horth, 2004 \\
\hline & & / & & Humphrey, 2019 \\
\hline & & - & Xiphophorus helleri & $\begin{array}{l}\text { Dürr, } 1996 \text { and Becker, } \\
1997 \text { in: Franck et al., } 2001\end{array}$ \\
\hline & Hunting activities by predator & / & Gambusia holbrooki & Humphrey, 2019 \\
\hline & & - & Xiphophorus helleri & $\begin{array}{l}\text { Dürr, } 1996 \text { and Becker, } \\
1997 \text { in: Franck et al., } 2001\end{array}$ \\
\hline $\begin{array}{l}\text { Sulfidic } \\
\text { springs }\end{array}$ & $\begin{array}{l}\text { Dichotomous choice test (females from } \\
\text { sulfidic spring) }\end{array}$ & $\begin{array}{l}\text { / unspotted females } \\
+ \text { spotted females }\end{array}$ & Poecilia mexicana & Culumber et al., 2014 \\
\hline Turbidity & $\begin{array}{l}\text { School choice experiments in turbid } \\
\text { conditions compared to clear } \\
\text { conditions }\end{array}$ & + & Xiphophorus helleri & Franck et al., 2001 \\
\hline \multirow[t]{4}{*}{ Temperature } & Simulated population model & $\begin{array}{l}\text { Seasonal changes around an } \\
\text { evolutionarily stable mean }\end{array}$ & Gambusia holbrooki & $\begin{array}{l}\text { Horth and Panayotova, } \\
2012\end{array}$ \\
\hline & $\begin{array}{l}\text { Simulated population model in } \\
\text { response to climate change }\end{array}$ & - & & $\begin{array}{l}\text { Panayotova and Horth, } \\
2018\end{array}$ \\
\hline & Penetrance of pattern expression & Higher in winter temperatures & Gambusia holbrooki & Angus, 1989; Horth, 2006 \\
\hline & & & Poecilia latipinna & $\begin{array}{l}\text { Schröder, 1964; Angus, } \\
\text { 1983; Angus et al., } 1999\end{array}$ \\
\hline
\end{tabular}

\section{CONCLUSION}

Melanin-based pigmentation patterns correlate with other traits across vertebrates through a variety of potential molecular and evolutionary mechanisms (revs.: Gray and McKinnon, 2007; Ducrest et al., 2008; Forsman et al., 2008; McKinnon and Pierotti, 2010; Peiman and Robinson, 2017; San-Jose and Roulin, 2018). Poeciliids have proven a tractable model for studying pigmentation-phenotype correlations, so we have presented here the melanic side-spotting pattern as a model for investigating the mechanisms underlying the evolution of similar color patterns and their correlations with other traits across populations, species, and genera. Specific results are summarized in Table 2. Although the development and inheritance of melanic sidespotting patterns are well known, we still do not understand the genetics of the pattern or all aspects of the pigment cells' biology. Most of the research on correlated traits focuses on a subset of populations from Xiphophorus species and Eastern Mosquitofish (G. holbrooki), so we recommend extending research into more poeciliid populations, species, and genera to determine whether 
the results reviewed here are generalizable trends. Little is known about physiological correlates and life history traits of spotted morphs. Spotted males have altered social conflict behavior and social groups compared to unspotted males. The melanic sidespotting pattern is generally uncommon in populations despite being an evolutionarily stable phenotype, so multiple positive and negative selective pressures are presumed to act upon it and its correlated traits. Predation appears to be an important negative frequency-dependent selective pressure, but social interactions may also function in the frequency-dependent selection that maintains the spotted morph at a low population frequency. Physical environmental factors are likely also important, but only a couple studies on water conditions exist. It is unclear whether sexual selection acts upon the melanic side-spotting pattern, and it may depend on a variety of factors such as population and species, morph frequency, and social and physical environment. Finally, whether melanic side-spotting patterns arose through homologous, convergent, and/or parallel evolution within and across Poeciliid species remains to be determined.

\section{FUTURE STUDIES}

Throughout this review, we identified what is still unknown within specific biological fields for the melanic side-spotting pattern in poeciliids. Here, we outline key research questions that may serve as a framework for future studies:

1. Which molecular mechanisms (sequential causation, coexpression, linkage disequilibrium, and pleiotropy) and/or evolutionary mechanisms (correlational selection, coadaptive selection, co-dependence, and co-specialization) underlie the correlation between melanic side-spotting patterns and other phenotypic traits?

2. Which molecular signaling systems (e.g., peptide hormones, amino acid hormones, monoamines, sex steroids, and neurotransmitters) affect the expression of the melanic side-spotting pattern, or are differentially expressed between morphs?

3. What gene(s) determine the presence or expression of the melanic side-spotting pattern to create the variation seen among populations and species? Do identified gene(s) pleiotropically affect or link to other molecular signaling systems that affect other phenotypic traits, such as physiology, life history, or behavior?

\section{REFERENCES}

Adam, D., Mäueler, W., and Schartl, M. (1991). Transcriptional activation of the melanoma inducing Xmrk oncogene in Xiphophorus. Oncogene 6, 73-80. doi: 10.1007/978-3-642-65700-9_4

Anders, A., and Anders, F. (1978). Etiology of cancer as studied in the platyfishswordtail system. Biochim. Biophys. Acta 516, 61-95. doi: 10.1016/0304419X(78)90004-5

Anders, A., Anders, F., and Klinke, K. (1973). "Regulation of gene expression in the Gordon-Kosswig melanoma system," in Genetics and Mutagenesis of Fish, ed. J. H. Schröder (Berlin: Springer), 33-52.
4. Does manipulation of molecular signaling systems that affect life history, physiology, or behavior also affect the presence or expression of the melanic side-spotting pattern, or vice versa?

5. Does the melanic side-spotting pattern or a correlated trait have an effect that is more disadvantageous in females than males that could lead to sexually antagonistic selection (and thus higher expression of the pattern in males)?

6. Are the correlated physiological, behavioral, and life history traits identified in this review a general trend across poeciliid populations, species, and genera? How do these correlated traits affect fitness of the melanic side-spotting pattern, especially survival and reproduction?

7. What social and physical environmental factors drive or break correlations in physiological, behavioral, or life history traits with melanic side-spotting patterns?

8. How do social and physical environmental factors interact with the pattern and its correlated traits to affect morph fitness? How do these interactions affect the maintenance and frequency of the melanic side-spotting pattern in populations and species?

9. What is the evolutionary origin of the polymorphic melanic side-spotting pattern? Did these similar patterns arise through homologous, convergent, and/or parallel evolution within and across species?

\section{AUTHOR CONTRIBUTIONS}

TZ conducted the review and synthesis of the literature and created all figures and tables. Both authors wrote and contributed to the manuscript and approved the submitted version.

\section{FUNDING}

TZ was financially supported by Florida International University through the Presidential Fellowship and Teaching Assistantships.

\section{ACKNOWLEDGMENTS}

We thank the members of PKS's lab who provided valuable comments on the structure and presentation of this review article. We also thank our reviewers for their feedback on content, structure, and presentation.

Anders, F., and Klinke, K. (1965). Untersuchungen über die erbbedingte Aminosäuren-konzentration, Farbgenmanifestation und Tumorbildung bei lebendgebärenden Zahnkarpfen (Poeciliidae). Z. Vererbungsl. 96, 49-65.

Anders, F., Schartl, M., Barnekow, A., and Anders, A. (1984). Xiphophorus as an in vivo model for studies on normal and defective control of oncogenes. $A d v$. Cancer Res. 42, 191-275. doi: 10.1016/S0065-230X(08)60459-5

Angus, R. A. (1983). Genetic analysis of melanistic spotting in Sailfin Mollies. J. Hered. 72, 81-84. doi: 10.1093/oxfordjournals.jhered.a109745

Angus, R. A. (1989). Inheritance of melanistic pigmentation in the Eastern Mosquitofish. J. Hered. 80, 387-392. doi: 10.1093/oxfordjournals.jhered. a110880 
Angus, R. A., Dass, B., and Blanchard, P. D. (1999). Quantification of the expression of a temperature-sensitive pigment allele in Sailfin Mollies (Poecilia latipinna) by image analysis. Pigment Cell Res. 12, 126-130. doi: 10.1111/j.1600-0749. 1999.tb00752.x

Atz, J. W. (1962). Effects of hybridization on pigmentation in fishes of the genus Xiphophorus. Zoologica 47, 153-181.

Basolo, A. L. (2006). Genetic linkage and color polymorphism in the Southern Platyfish (Xiphophorus maculatus): a model system for studies of color pattern evolution. Zebrafish 3, 65-83. doi: 10.1089/zeb.2006.3.65

Becker, N. (1997). Experimente zum Einfluß eines Raubfeindes auf den Makromelanophorenpolymorphismus des Grünen Schwertträgers (Xiphophorus helleri). Diploma thesis, University of Hamburg, Hamburg.

Bellamy, A. W. (1924). Bionomic studies on certain teleosts (Poeciliinae) I. Statement of problems, description of material, and general notes on life histories and breeding behavior under laboratory conditions. Genetics 9, 513-529.

Bellamy, A. W. (1928). Bionomic studies on certain teleosts (Poeciliinae). II. Color pattern inheritance and sex in Platypoecilus maculatus (Günth.). Genetics 13, 226-232.

Bellamy, A. W. (1936). Inter-specific hybrids in Platypoecilus: one species ZZ-WZ; the other XY-XX. Proc. Natl. Acad. Sci. U.S.A. 22, 531-536. doi: 10.1073/pnas. 22.9.531

Bisazza, A., and Pilastro, A. (2000). Variation of female peference for male coloration in the Eastern Mosquitofish Gambusia holbrooki. Behav. Genet. 30, 207-212. doi: 10.1023/A:1001914208075

Bisazza, A., Vaccari, G., and Pilastro, A. (2001). Female mate choice in a mating system dominated by male sexual coercion. Behav. Ecol. 12, 59-64. doi: 10. 1093/oxfordjournals.beheco.a000379

Bonner, M. (1980). Predation of bluefill, Lepomis macrochirus, on Models of Melanistic and Normal Male Mosquitofish, Gambusia affinis holbrooki. Master's thesis, North Carolina A\&T University, Greensboro, NC.

Borowsky, R. (1973). Melanomas in Xiphophorus variatus (Pisces, Poeciliidae) in the absence of hybridization. Experientia 29, 1431-1433. doi: 10.1007/ BF01922860

Bradner, J., and McRobert, S. P. (2001a). Background colouration influences body colour segregation in mollies. J. Fish Biol. 59, 673-681. doi: 10.1111/j.10958649.2001.tb02371.x

Bradner, J., and McRobert, S. P. (2001b). The effect of shoal size on patterns of body colour segregation in mollies. J. Fish Biol. 59, 960-967. doi: 10.1111/j. 1095-8649.2001.tb00164.x

Culumber, Z. W. (2014). Pigmentation in Xiphophorus: an emerging system in ecological and evolutionary genetics. Zebrafish 11, 57-70. doi: 10.1089/zeb. 2013.0939

Culumber, Z. W. (2016). Variation in the evolutionary integration of melanism with behavioral and physiological traits in Xiphophorus variatus. Evol. Ecol. 30, 9-20. doi: 10.1007/s10682-015-9807-2

Culumber, Z. W., Bautista-Hernández, C. E., Monks, S., Arias-Rodriguez, L., and Tobler, M. (2014). Variation in melanism and female preference in proximate but ecologically distinct environments. Ethology 120, 1090-1100. doi: 10.1111/ eth. 12282

Culumber, Z. W., Engel, N., Travis, J., and Hughes, K. A. (2020). Larger female brains do not reduce male sexual coercion. Anim. Behav. 160, 15-24. doi: 10.1016/j.anbehav.2019.11.018

Culumber, Z. W., Kraft, B., Lemakos, V., Hoffner, E., Travis, J., and Hughes, K. A. (2018). GxG epistasis in growth and condition and the maintenance of genetic polymorphism in Gambusia holbrooki. Evolution 72, 1146-1154. doi: $10.1111 /$ evo.13474

Ducrest, A., Keller, L., and Roulin, A. (2008). Pleiotropy in the melanocortin system, coloration and behavioural syndromes. Trends Ecol. Evol. 23, 502-510. doi: 10.1016/j.tree.2008.06.001

Dürr, S. (1996). Das Beuteerwerbsvehalten des Lebendgebärenden Hechtkärpflings (Belonesox belizanus) Gegenüber Gefleckten und Ungefleckten Morphen des Grünen Schwertträgers (Xiphophorus helleri). Diploma thesis, University of Hamburg, Hamburg.

Endler, J. A. (1988). Frequency-dependent predation, crypsis and aposematic coloration. Philos. Trans. R. Soc. Lond. B Biol. Sci. 319, 505-523. doi: 10.1098/ rstb.1988.0062
Evans, J. P., Pilastro, A., and Schlupp, I. (2011). Ecology and Evolution of Poeciliid Fishes. Chicago, IL: University of Chicago Press. doi: 10.7208/chicago/ 9780226222769.001.0001

Fernandez, A. A., and Bowser, P. R. (2008). Two cases of non-hybrid melanoma formation in Xiphophorus nezahualcoyotl Rauchenberger, Kallmann \& Morizot. J. Fish Biol. 72, 292-300. doi: 10.1111/j.1095-8649.2007.01691.x

Fernandez, A. A., and Morris, M. R. (2008). Mate choice for more melanin as a mechanism to maintain a functional oncogene. Proc. Natl. Acad. Sci. U.S.A. 105, 13503-13507. doi: 10.1073/pnas.0803851105

Forsman, A., Ahnesiö, J., Caesar, S., and Karlsson, M. (2008). A model of ecological and evolutionary consequences of color polymorphism. Ecology 89, 34-40. doi: 10.1890/07-0572.1

Franck, D., Dikomey, M., and Schartl, M. (2001). Selection and the maintenance of a colour pattern polymorphism in the Green Swordtail (Xiphophorus helleri). Behaviour 138, 467-486. doi: 10.1163/156853901750382115

Franck, D., Klamroth, B., Taebel-Hellwig, A., and Schartl, M. (1998). Home ranges and satellite tactics of male green swordtails (Xiphophorus helleri) in nature. Behav. Process. 43, 115-123. doi: 10.1016/S0376-6357(98)00003-5

Fraser, A. C., and Gordon, M. (1929). The genetics of Platypoecilus. II. The linkage of two sex-linked characters. Genetics 14, 160-179.

Gordon, H., and Gordon, M. (1957). Maintenance of polymorphism by potentially injurious genes in eight natural populations of the platyfish, Xiphophorus maculatus. J. Genet. 55, 1-44. doi: 10.1007/BF02981614

Gordon, M. (1927). The genetics of a viviparous top-minnow Platypoecilus; the inheritance of two kinds of melanophores. Genetics 12, 253-283.

Gordon, M. (1928). Pigment inheritance in the Mexican Killifish: interaction of factors in Platypoecilus maculatus. J. Hered. 19, 551-556. doi: 10.1093/ oxfordjournals.jhered.a102942

Gordon, M. (1931a). Hereditary basis of melanosis in hybrid fishes. Am. J. Cancer $15,1495-1593$.

Gordon, M. (1931b). Morphology of the heritable color patterns in the Mexican Killifish, Platypoecilus. Am. J. Cancer 15, 732-787.

Gordon, M. (1937). Genetics of Platypoecilus III. Inheritance of sex and crossing over of the sex chromosomes in the platyfish. Genetics 22, 376-392.

Gordon, M. (1943). Genetic studies of speciation in the swordtail-platyfish group and of the experimentally produced hybrids. Trans. N.Y. Acad. Sci. 5, 63-71. doi: 10.1111/j.2164-0947.1943.tb00867.x

Gordon, M. (1946). Interchanging genetic mechanisms for sex determination: in fishes under domestication. J. Hered. 37, 307-320. doi: 10.1093/oxfordjournals. jhered.a105541

Gordon, M. (1947). Genetics of Platypoecilus maculatus. IV. The sex determining mechanism in two wild populations of the Mexican Platyfish. Genetics 32, 8-17.

Gordon, M. (1948). Effects of five primary genes on the site of melanomas in fishes and the influence of two color genes on their pigmentation. Ann. N.Y. Acad. Sci. 4, 216-268.

Gordon, M. (1951). Genetics of Platypoecilus maculatus. V. Heterogametic sexdetermining mechanism in females of a domesticated stock originally from British Honduras. Gordon 36, 127-134.

Gordon, M., and Smith, G. M. (1938). The production of a melanotic neoplastic disease in fishes by selective matings: IV. Genetics of geographical species hybrids. Am. J. Cancer 34, 543-565.

Gould, J. L., Elliott, S. L., Masters, C. M., and Mukerji, J. (1999). Female preferences in a fish genus without female mate choice. Curr. Biol. 9, 497-500. doi: 10.1016/ S0960-9822(99)80217-6

Gray, S. M., and McKinnon, J. S. (2007). Linking color polymorphism maintenance and speciation. Trends Ecol. Evol. 22, 71-79. doi: 10.1016/j.tree.2006. 10.005

Gutbrod, H., and Schartl, M. (1999). Intragenic sex-chromosomal crossovers of Xmrk oncogene alleles affect pigment pattern formation and the severity of melanoma in Xiphophorus. Genetics 151, 773-783.

Gutiérrez, M. L., and García, G. (2007). Inheritance of a dominant spotted melanic mutation in the livebearing fish Phalloceros caudimaculatus var. reticulata from "Bañados del Este" Reserve of Biosphere Site in Uruguay. Cytologia 72, 131-139. doi: 10.1508/cytologia.72.131

Gutiérrez, M. L., and García, G. (2011). A preliminary linkage map using spotted melanic laboratory strains of the livebearing fish Phalloceros caudimaculatus var. reticulata (Cyprinodontiformes: Poeciliidae). J. Genet. 92, 66-71. doi: 10.1007/s12041-011-0085-7 
Halaban, R., Svedine, S., Cheng, E., Smicun, Y., Aron, R., and Hebert, D. N. (2000). Endoplasmic reticulum retention is a common defect associated with tyrosinase-negative albinism. Proc. Natl. Acad. Sci. U.S.A. 97, 5889-5894. doi: 10.1073/pnas.97.11.5889

Haskins, C. P., Haskins, E. F., and Hewitt, R. E. (1960). Pseudogamy as an evolutionary factor in the Poeciliid Fish Mollienisia formosa. Evolution 14, 473-483. doi: 10.2307/2405996

Häussler, G. (1928). Über Melanombildungen bei Bastarden von Xiphophorus helleri und Platypoecilus maculatus var. Rubra. Klin. Wochenschr. 7, 1561-1562. doi: 10.1007/BF01748470

Hishida, T.-O., and Kawamoto, N. (1970). Androgenic and male-inducing effects of 11-ketotestosterone on a teleost, the medaka (Oryzias latipes). J. Exp. Zool. 173, 279-283. doi: 10.1002/jez.1401730306

Horth, L. (2003). Melanic body colour and aggressive mating behaviour are correlated traits in male mosquitofish (Gambusia holbrooki). Proc. Biol. Sci. 270, 1033-1040. doi: $10.1098 / \mathrm{rspb} .2003 .2348$

Horth, L. (2004). Predation and the persistence of melanic male mosquitofish (Gambusia holbrooki). J. Evol. Biol. 17, 672-679. doi: 10.1111/j.1420-9101.2004. 00710.x

Horth, L. (2006). A sex-linked allele, autosomal modifiers and temperaturedependence appear to regulate melanism in male mosquitofish (Gambusia holbrooki). J. Exp. Biol. 209, 4938-4945. doi: 10.1242/jeb.02599

Horth, L., Binckley, C., Wilk, R., Reddy, P., and Reddy, A. (2010). Color, body size, and genitalia size are correlated traits in Eastern Mosquitofish (Gambusia holbrooki). Copeia 2010, 196-202. doi: 10.1643/CG-09-044

Horth, L., Gauthier, D., and Vogelbein, W. (2013). Heritable melanism and parasitic infection both result in black-spotted mosquitofish. Southeast. Nat. 12, 209-216. doi: 10.1656/058.012.0116

Horth, L., and Panayotova, I. N. (2012). Simulating the maintenance of a rare fish morph experiencing negative frequency dependent selection. Biosystems 110, 149-155. doi: 10.1016/j.biosystems.2012.08.005

Horth, L., and Travis, J. (2002). Frequency-dependent numerical dynamics in mosquitofish. Proc. Biol. Sci. 269, 2239-2247. doi: 10.1098/rspb.2002.2143

Humm, D. G., and Young, R. S. (1956). The embryological origin of pigment cells in platyfish-swordtail hybrids. Zoologica 41, 1-10.

Humphrey, E. (2019). Stress and Coloration as Mediators of Behavioral and Physiological Variation. Ph.D. thesis, Florida State University, Tallahassee, FL.

Huxley, J. (1955). Morphism and evolution. Heredity 9, 1-52. doi: 10.1038/hdy. 1955.1

Kallman, K. D. (1965). Genetics and geography of sex determination in the poeciliid fish, Xiphophorus maculatus. Zoologica 50, 151-190.

Kallman, K. D. (1971). Inheritance of melanophore patterns of the poeciliid fish Xiphophorus montezumae cortezi and the genetic control of the sexual maturation process and adult size. Zoologica 56, 77-94.

Kallman, K. D. (1975). "The Platyfish, Xiphophorus maculatus," in Handbook of Genetics, ed. R. C. King (New York, N.Y: Plenum Press), 81-132. doi: 10.1007/ 978-1-4613-4470-4_6

Kallman, K. D. (1983). The sex determining mechanism of the poeciliid fish, Xiphophorus montezumae, and the genetic control of the sexual maturation process and adult size. Copeia 1983, 755-769. doi: 10.2307/1444343

Kallman, K. D., and Atz, J. W. (1966). Gene and chromosome homology in fishes of genus Xiphophorus. Zoologica 51, 107-141.

Kallman, K. D., and Borkoski, V. (1978). A sex-linked gene controlling the onset of sexual maturity in female and male platyfish (Xiphophours maculatus), fecundity in females and adult size in males. Genetics 89, 79-119.

Karplus, I., and Algom, D. (1996). Polymorphism and pair formation in the mosquitofish Gambusia holbrooki (Pisces: Poeciliidae). Environ. Biol. Fish. 45, 169-176. doi: 10.1007/BF00005231

Kazianis, S., and Borowsky, R. (1995). Stable association of a pigmentation allele with an oncogene: nonhybrid melanomas in Xiphophorus variatus. J. Hered. 86, 199-203. doi: 10.1093/oxfordjournals.jhered.a111562

Ketterson, E. D., and Nolan, V. Jr. (1999). Adaptation, exaptation, and constraint: a hormonal perspective. Am. Nat. 154, S4-S25. doi: 10.1086/303280

Kidson, S. H., and Fabian, B. C. (1981). The effect of temperature on tyrosinase activity in Himalayan mouse skin. J. Exp. Zool. 215, 91-97. doi: 10.1002/jez. 1402150111

Kottler, A. V., and Schartl, M. (2018). The colorful sex chromosomes of teleost fish. Genes 9:233. doi: 10.3390/genes9050233
Kottler, V. A., Feron, R., Nanda, I., Klopp, C., Du, K., Kneitz, S., et al. (2020). Independent origin of XY and ZW sex determination mechanisms in mosquitofish sister species. Genetics 214, 193-209. doi: 10.1534/genetics.119. 302698

Koutsikos, N., Economou, A. N., Vardakas, L., Kommatas, D., and Zogaris, S. (2017). First confirmed record of an established population of Sailfin Molly, Poecilia Latipinna (Actinopterygii: Cyprinodontiformes: Poeciliidae), in Europe. Acta Ichthyol. Piscat. 47, 311-315. doi: 10.3750/AIEP/022 34

Koßwig, C. (1927). Über Bastarde der Teleostier Platypoecilus und Xiphophorus. Z. Indukt. Abstamm. Vererbungsl. 44:253. doi: 10.1007/BF01740990

Koßwig, C. (1929). Das Gen in fremder Erbmasse. Nach Kreuzungsversuchen mit Zahnkarpfen. Züchter 1, 152-157. doi: 10.1007/BF01812340

Koßwig, C. (1938). Über einen neuen Farbencharakter des Platypoecilus maculatus. Fac. Sci. Univ. Istanbul 3, 1-8.

Kraft, B. (2016). Role of Indirect and Direct Genetic Effects in Modification of Behavior and Maintenance of Color Polymorphism in Male Gambusia holbrooki. Ph.D. thesis, Florida State University, Tallahassee, FL.

Kraft, B., Lemakos, V. A., Travis, J., and Hughes, K. A. (2018). Pervasive indirect genetic effects on behavioral development in polymorphic Eastern Mosquitofish. Behav. Ecol. 29, 289-300. doi: 10.1093/beheco/arx180

Kraft, B., Williams, E., Lemakos, V. A., Travis, J., and Hughes, K. A. (2016). Genetic color morphs in the Eastern Mosquitofish experience different social environments in the wild and laboratory. Ethology 122, 869-880. doi: 10.1111/ eth. 12531

Kwon, B. S., Halaban, R., and Chintamaneni, C. (1989). Molecular basis of mouse Himalayan mutation. Biochem. Biophys. Res. Commun. 161, 252-260. doi: 10.1016/0006-291X(89)91588-X

Lamatsch, D. K., Stöck, M., Fuchs, R., Döbler, M., Wacker, R., Parzefall, J., et al. (2010). Morphology, testes development and behaviour of unusual triploid males in microchromosome-carrying clones of Poecilia formosa. J. Fish Biol. 77, 1459-1487. doi: 10.1111/j.1095-8649.2010.02766.x

Lamatsch, D. K., Trifonov, V., Schories, S., Epplen, J. T., Schmid, M., and Schartl, M. (2011). Isolation of a cancer-associated microchromosome in the spermdependent parthenogen Poecilia formosa. Cytogenet. Genome Res. 135, 135-142. doi: $10.1159 / 000331271$

Lampert, K. P., Schmidt, C., Fischer, P., Volff, J.-N., Hoffmann, C., Muck, J., et al. (2010). Determination of onset of sexual maturation and mating behavior by Melanocortin Receptor 4 polymorphisms. Curr. Biol. 20, 1729-1734. doi: 10.1016/j.cub.2010.08.029

Lampert, K. P., Steinlein, C., Schmid, M., Fischer, P., and Schartl, M. (2007). A haploid-diploid-triploid mosaic of the Amazon molly, Poecilia formosa. Cytogenet. Genome Res. 119, 131-134. doi: 10.1159/000109629

Ledesma, J. M., and McRobert, S. P. (2008). Innate and learned shoaling preferences based on body coloration in juvenile mollies, Poecilia latipinna. Ethology 114, 1044-1048. doi: 10.1111/j.1439-0310.2008.01560.x

Liu, T. F., Kandala, G., and Setaluri, V. (2001). PDZ Domain Protein GIPC interacts with the cytoplasmic tail of melanosomal membrane protein gp75 (Tyrosinase-related Protein-1). J. Biol. Chem. 276, 35768-35777. doi: 10.1074/ jbc.M103585200

Lu, Y., Boswell, M., Boswell, W., Kneitz, S., Hausmann, M., Klotz, B., et al. (2017). Molecular genetic analysis of the melanoma regulatory locus in Xiphophorus interspecies hybrids. Mol. Carcinog. 56, 1935-1944. doi: 10.1002/mc. 22651

Mac Intyre, P. A. (1961). Deleterious effects of a gene causing excessive pigmentation in the platyfish. J. Hered. 52, 292-294. 10.1093/oxfordjournals. jhered.a107100

Martin, R. G. (1977). Density-dependent aggressive advantage in melanistic male mosquitofish Gambusia affinis holbrooki (Girard). Fla. Sci. 40, 393-400.

Martin, R. G. (1984). Proportion of melanistic offspring resulting from cross between melanistic male mosquitofish and normal female mosquitofish, Gambusia affinis holbrooki. J. Elisha Mitchell Sci. Soc. 100, 121-123.

Martin, R. G. (1986). Behavioral response of female mosquitofish, Gambusia affinis holbrooki, to normal versus melanistic male mosquitofish. J. Elisha Mitchell Sci. Soc. 102, 129-136.

McDowall, R. M. (1999). Further feral poeciliid fish in New Zealand fresh waters, with a key to species. N.Z. J. Mar. Freshw. Res. 33, 673-682. doi: 10.1080/ 00288330.1999 .9516910 
McKinnon, J. S., and Pierotti, M. E. R. (2010). Colour polymorphism and correlated characters: genetic mechanisms and evolution. Mol. Ecol. 19, 5101-5125. doi: 10.1111/j.1365-294X.2010.04846.x

McNeil, D., and Wilson, P. (2008). The Speckled Livebearer (Phalloceros caudimaculatus): A New Alien Fish for South Australia. Adelaide: South Australian Research and Development Institute.

McRobert, S. P., and Bradner, J. (1998). The influence of body coloration on shoaling preferences in fish. Anim. Behav. 56, 611-615. doi: 10.1006/anbe.1998. 0846

Meffe, G. K., and Snelson, F. F. (1989). Ecology and Evolution of Livebearing Fishes (Poeciliidae). Englewood Cliffs, NJ: Prentice Hall.

Menzel, B. W., and Darnell, R. M. (1973). Systematics of Poecilia mexicana (Pisces: Poeciliidae) in Northern Mexico. Copeia 1973, 225-237. doi: 10.2307/1442961

Meyer, C. I., Kaufman, R., and Cech, J. J. (2006). Melanin pattern morphs do not differ in metabolic rate: implications for the evolutionary maintenance of a melanophore polymorphism in the green swordtail, Xiphophorus helleri. Naturwissenschaften 93, 495-499. doi: 10.1007/s00114-006-0134-x

Myers, G. S. (1925). Concerning melanodimorphism in killifishes. Copeia 137, 105-107. doi: $10.2307 / 1436091$

Nanda, I., Schlupp, I., Lamatsch, D. K., Lampert, K. P., Schmid, M., and Schartl, M. (2007). Stable inheritance of host species-derived microchromosomes in the gynogenetic fish Poecilia formosa. Genetics 177, 917-926. doi: 10.1534/genetics. 107.076893

Nelson, C. M., and Planes, K. (1993). Female choice of nonmelanistic males in laboratory populations of the mosquitofish, Gambusia holbrooki. Copeia 1993, 1143-1148. doi: 10.2307/1447097

Nelson, J. S. (1983). The tropical fish fauna in Cave and Basin Hotsprings Drainage, Banff National Park, Alberta. Can. Field Nat. 97, 255-261.

Oliveira, R. F., Hirschenhauser, K., Carneiro, L. A., and Canario, A. V. M. (2002). Social modulation of androgen levels in male teleost fish. Comp. Biochem. Physiol. B Biochem. Mol. Biol. 132, 203-215. doi: 10.1016/S1096-4959(01) 00523-1

Panayotova, I. N., and Horth, L. (2018). Modeling the impact of climate change on a rare color morph in fish. Ecol. Modell. 387, 10-16. doi: 10.1016/j.ecolmodel. 2018.08.008

Parichy, D. M., and Spiewak, J. E. (2015). Origins of adult pigmentation: diversity in pigment stem cell lineages and implications for pattern evolution. Pigment Cell Melanoma Res. 28, 31-50. doi: 10.1111/pcmr.12332

Peiman, K. S., and Robinson, B. W. (2017). Comparative analyses of phenotypic trait covariation within and among populations. Am. Nat. 190, 451-468. doi: 10.1086/693482

Perlmutter, A., and Potter, H. (1988). Hyperthermic suppression of a genetically programmed melanoma in hybrids of fishes: genus Xiphophorus. J. Cancer Res. Clin. Oncol. 114, 359-362. doi: 10.1007/BF02128178

Petrescu-Mag, I. V., Lozinsky, R. L., Csép, L., and Petrescu-Mag, R. M. (2008). Vegetation and predators mediate color pattern frequencies in Poecilia sphenops Valenciennes. Aquac. Aquar. Conserv. Legis. 1, 51-61.

Rauchenberger, M., Kallman, K. D., and Morizot, D. C. (1990.) "Monophyly and geography of the Río Pánuco basin swordtails (genus Xiphophorus) with descriptions of four new species," in American Museum Novitates (New York, NY: American Museum of Natural History), 1-41.

Regan, J. D. (1961). Melanism in the Poeciliid Fish, Gambusia affinis (Baird and Girard). Am. Midl. Nat. 65, 139-143. doi: 10.2307/2423009

San-Jose, L. M., and Roulin, A. (2017). Genomics of coloration in natural animal populations. Philos. Trans. R. Soc. Lond. B Biol. Sci. 372, 20160337. doi: 10.1098/ rstb.2016.0337

San-Jose, L. M., and Roulin, A. (2018). Toward understanding the repeated occurrence of associations between melanin-based coloration and multiple phenotypes. Am. Nat. 192, 111-130. doi: 10.1086/698010

San-Jose, L. M., and Roulin, A. (2020). On the potential role of the neural crest cells in integrating pigmentation into behavioral and physiological syndromes. Front. Ecol. Evol. 8:278. doi: 10.3389/fevo.2020.00278

Schartl, A., Hornung, U., Nanda, I., Wacker, R., Müller-Hermelink, H.-K., Schlupp, I., et al. (1997). Susceptibility to the development of pigment cell tumors in a clone of the Amazon Molly, Poecilia formosa, introduced through a microchromosome. Cancer Res. 57, 2993-3000.

Schartl, A., Malitschek, B., Kazianis, S., Borowsky, R., and Schartl, M. (1995). Spontaneous melanoma formation in nonhybrid Xiphophorus. Cancer Res. 55, 159-165.
Schartl, M. (1990). Homology of melanoma-inducing loci in the genus Xiphophorus. Genetics 126, 1083-1091.

Schartl, M. (2008). Evolution of Xmrk: an oncogene, but also a speciation gene? Bioessays 30, 822-832. doi: 10.1002/bies.20807

Schartl, M., and Schröder, J. H. (1987). A new species of the genus Xiphophorus HECKEL 1848, endemic to northern Coahuila, Mexico (Pisces: Poeciliidae). Senckenberg. Biol. 68, 311-321.

Schartl, M., and Walter, R. B. (2016). "Xiphophorus and medaka cancer models," in Cancer and Zebrafish: Mechanisms, Techniques, and Models, ed. D. M. Langenau (Cham: Springer), 531-552. doi: 10.1007/978-3-319-30654-4_23

Schmidt, E. R. (1978). Chromatophore development and cell interactions in the skin of Xiphophorine fish. Wilhelm Roux. Arch. Dev. Biol. 184, 115-134. doi: 10.1007/BF00848221

Schröder, J. H. (1964). Genetische Untersuchungen an domestizierten Stämmen der Gattung Mollienesia (Poeciliidae). Zool. Beträge 10, 369-463.

Schultz, R. J., and Kallman, K. D. (1968). Triploid hybrids between the all-female teleost Poecilia formosa and Poecilia sphenops. Nature 219, 280-282. doi: 10. 1038/219280a0

Sinervo, B., and Svensson, E. (2002). Correlational selection and the evolution of genomic architecture. Heredity 89, 329-338. doi: 10.1038/sj.hdy.6800148

Snelson, F. F., Smith, R. E., and Bolt, M. R. (1986). A melanistic female mosquitofish, Gambusia affinish holbrooki. Am. Midl. Nat. 115, 413-415. doi: $10.2307 / 2425877$

Taylor, S. A., Burt, E., Hammond, G., and Relyea, K. (1996). Female mosquitofish (Gambusia affinis holbrooki) prefer normally pigmented males to melanistic males. J. Comp. Psychol. 110, 260-266. doi: 10.1037/0735-7036.110. 3.260

Trendall, J. T., and Johnson, M. S. (1981). Identification by anatomy and gel electrophoresis of Phalloceros caudimaculatus (Poeciliidae), previously mistaken for Gambusia affinis holbrooki (Poeciliidae). Aust. J. Mar. Freshw. Res. 32, 993-996. doi: 10.1071/MF9810993

Turner, B. J., Brett, B.-L. H., and Miller, R. R. (1980). Interspecific hybridization and the evolutionary origin of a gynogenetic fish, Poecilia formosa. Evolution 34, 917-922. doi: 10.2307/2407997

Vielkind, J., Haas-Andela, H., and Anders, F. (1976). DNA-mediated transformation in the platyfish-swordtail melanoma system. Experientia 32, 1043-1045. doi: 10.1007/BF01933962

Vielkind, J., Haas-Andela, H., Vielkind, U., and Anders, F. (1982). The induction of a specific pigment cell type by total genomic DNA injected into the neural crest region of fish embryos of the genus Xiphophorus. Mol. Gen. Genet. 185, 379-389. doi: 10.1007/BF00334128

Vielkind, J., and Vielkind, U. (1982). Melanoma formation in fish of the genus Xiphophorus: a genetically-based disorder in the determination and differentiation of a specific pigment cell. Can. J. Genet. Cytol. 24, 133-149. doi: $10.1139 / \mathrm{g} 82-013$

Vielkind, U. (1976). Genetic control of cell differentiation in platyfishswordtail melanomas. J. Exp. Zool. 196, 197-203. doi: 10.1002/jez.140196 0207

Volff, J.-N., and Schartl, M. (2001). Variability of genetic sex determination in poeciliid fishes. Genetica 111, 101-110. doi: 10.1023/A:1013795415808

Walter, R. B., Hazlewood, L., and Kazianis, S. (2006). The Xiphophorus Genetic Stock Center Manual, eds K. D. Kallman and M. Schartl (San Marcos, TX: Texas State University).

Weis, S., and Schartl, M. (1998). The macromelanophore locus and the melanoma oncogene Xmrk are separate genetic entities in the genome of Xiphophorus. Genetics 149, 1909-1920.

Wilkins, A. S., Wrangham, R. W., and Fitch, W. T. (2014). The "Domestication Syndrome" in mammals: a unified explanation based on neural crest cell behavior and genetics. Genetics 197, 795-808. doi: 10.1534/genetics.114.165423

Williams, G. C. (1957). Pleiotropy, natural selection, and the evolution of senescence. Evolution 11, 398-411. doi: 10.2307/2406060

Wingfield, J. C. (1984). Environmental and endocrine control of reproduction in the song sparrow, Melospiza melodia: II. Agonistic interactions as environmental information stimulating secretion of testosterone. Gen. Comp. Endocrinol. 56, 417-424. doi: 10.1016/0016-6480(84)90084-4

Wingfield, J. C., and Sapolsky, R. M. (2003). Reproduction and resistance to stress: When and How. J. Neuroendocrinol. 15, 711-724. doi: 10.1046/j.1365-2826. 2003.01033.x 
Wittbrodt, J., Adam, D., Malitschek, B., Mäueler, W., Raulf, F., Telling, A., et al. (1989). Novel putative receptor tyrosine kinase encoded by the melanomainducing $T u$ locus in Xiphophorus. Nature 341, 415-421. doi: 10.1038/341 $415 \mathrm{a} 0$

Zander, C. D. (1965). Die Geschlechtsbestimmung bei Xiphophorus montezumae cortezi Rosen (Pisces). Z. Vererbungsl. 96, 128-141. doi: 10.1007/BF008 88784

Zander, C. D. (1967). Ökologische und morphologische Beiträge zur Systematik und geographischen Verbeitung der Gattung Xiphophorus (Pisces). Mitt. Hamb. Zool. Mus. Inst. 64, 87-125.
Conflict of Interest: The authors declare that the research was conducted in the absence of any commercial or financial relationships that could be construed as a potential conflict of interest.

Copyright (๑) 2021 Zerulla and Stoddard. This is an open-access article distributed under the terms of the Creative Commons Attribution License (CC BY). The use, distribution or reproduction in other forums is permitted, provided the original author(s) and the copyright owner(s) are credited and that the original publication in this journal is cited, in accordance with accepted academic practice. No use, distribution or reproduction is permitted which does not comply with these terms. 